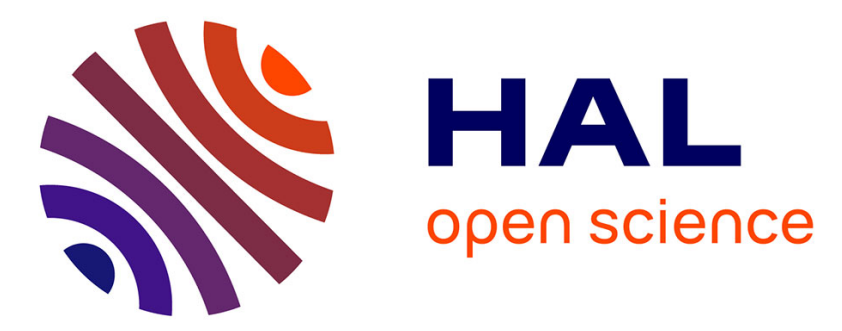

\title{
Nanomaterials for transdermal drug delivery: beyond the state of the art of liposomal structures
}

Roxana Jijie, Alexandre Barras, Rabah Boukherroub, Sabine Szunerits

\section{To cite this version:}

Roxana Jijie, Alexandre Barras, Rabah Boukherroub, Sabine Szunerits. Nanomaterials for transdermal drug delivery: beyond the state of the art of liposomal structures. Journal of materials chemistry B, 2017, 5 (44), pp.8653-8675. 10.1039/C7TB02529G . hal-02189348

\section{HAL Id: hal-02189348 \\ https://hal.science/hal-02189348}

Submitted on 19 Jul 2019

HAL is a multi-disciplinary open access archive for the deposit and dissemination of scientific research documents, whether they are published or not. The documents may come from teaching and research institutions in France or abroad, or from public or private research centers.
L'archive ouverte pluridisciplinaire HAL, est destinée au dépôt et à la diffusion de documents scientifiques de niveau recherche, publiés ou non, émanant des établissements d'enseignement et de recherche français ou étrangers, des laboratoires publics ou privés. 


\title{
Nanomaterials for transdermal drug delivery: beyond the state of the art of liposomal structures
}

\author{
Roxana Jijie, ${ }^{1}$ Alexandre Barras, ${ }^{1}$ Rabah Boukherroub ${ }^{1 *}$ and Sabine Szunerits ${ }^{1 *}$ \\ ${ }^{1}$ Univ. Lille, CNRS, Centrale Lille, ISEN, Univ. Valenciennes, UMR 8520, IEMN, F-59000 \\ Lille, France
}

\begin{abstract}
A wide range of biomedical materials have been proposed to meet the different needs for controlled oral or intravenous drug delivery. The advantages of oral delivery such as self-administration of a predetermined drug dose at defined time intervals makes it the most convenient means for the delivery of small molecular drugs. It fails however to delivery therapeutic macromolecules due to rapid degradation in the stomach and size-limited transport across the epithelium. The primary mode of administration of macromolecules is presently via injection. This administration mode is not without limitations, as the invasive nature of injections elicits pain and decreases patients' compliance. Alternative routes for drug delivery have been looked for, one being the skin. Delivery of drugs via the skin is based on the therapeutics penetrating the stratum corneum with the advantage of overcoming first-pass metabolism of drugs, to deliver drugs with a short-half-life time more easily and to eliminate frequent administrations to maintain constant drug delivery. The transdermal market still remains limited to a narrow range of drugs. The low permeability of the SC to water-soluble and macromolecular drugs poses significant challenges to transdermal administering via passive diffusion through the skin, as is the case for all topically administered drug formulations intended to bring the therapeutic into the general circulation. To widen the scope of drugs for transdermal delivery, new procedures to enhance skin permeation to hydrophilic drugs and macromolecules are under development. Next to the integration of skin enhancers into pharmaceutical formulations, nanoparticles based on lipid carrier have been widely considered and reviewed. While being briefly reviewed here, the main focus of this article is on current advancements using polymeric and metallic nanoparticles. Next to these passive technologies, the handful of active technologies for local and systemic transdermal drug delivery will be discussed and put into perspective. While passive approaches dominate the literature and the transdermal market, active delivery patches based on microneedles or iontophoresis approaches have shown great promise for transdermal drug delivery and have entered the market, in the last decade. This review gives an overall idea of the current activities in this field.
\end{abstract}

Keywords: transdermal delivery, nanoparticles, skin, drug, patches.

\section{Skin structure}

Among the multiple functions of mammalian skin, one of its major roles is to prevent invasion of the organism by viruses, bacteria, dust, allergens, toxic chemicals, UV irradiation and particulate materials, which may occur in the natural environment by acting as a defense barrier to threats from the external environment. ${ }^{1}$ On the other hand, the skin can be used as an entry port for therapeutic substrates by overcoming the mechanisms that confer the barrier properties to the skin. The skin's remarkable barrier properties are due in large to the stratum corneum (SC), consisting of corneocytes that are densely packed within the extracellular lipid matrix, organized as multiple lamellar bilayers (Figure 1A). This is often referred to as a "bricks and mortar" arrangement. Variations in the number

"To whom correspondence should be send to: sabine.szunerits@univ-lille1.fr 
of lamellar membranes (=lipid weight \%), membrane structure and/or lipid composition provide the structural bases for site-related variations in permeability. ${ }^{2}$ These highly hydrophobic lipids (the key species being ceramides, cholesterol, free fatty acids) prevent excessive loss of bodily water and likewise block the entry of most topically applied drugs, other than those that are lipid-soluble and of low molecular weight. It provides in addition a reservoir within which lipid-soluble drugs, such as topical corticosteroids, accumulate and be only slowly released. For most small penetrants, the intracellular route is thus favored, where these small molecules are able to move freely within the inter-cellular space and diffusion rates are governed largely by the lipophilicity of the drug.

From a physicochemical point of view, an ideal transdermal drug candidate has to meet a number of requirements such as high lipophilicity, low molecular weight ( $<500$ Dalton), sufficient solubility in water at $\mathrm{pH} 6$ to 7.4 (e.g. $\approx 0.05$ to $1 \mathrm{mg} / \mathrm{mL}$ if target delivery rate is in the mg range per day), and a suitable $\mathrm{pKa}$ (determines solubility of the un-ionized form at physiological $\mathrm{pH}$ ). Most of the FDAapproved transdermal patches are consequently limited to molecules such as nicotine, estradiol, fentanyl etc. (Table 1) using passive diffusion as mode of drug delivery.

(A)

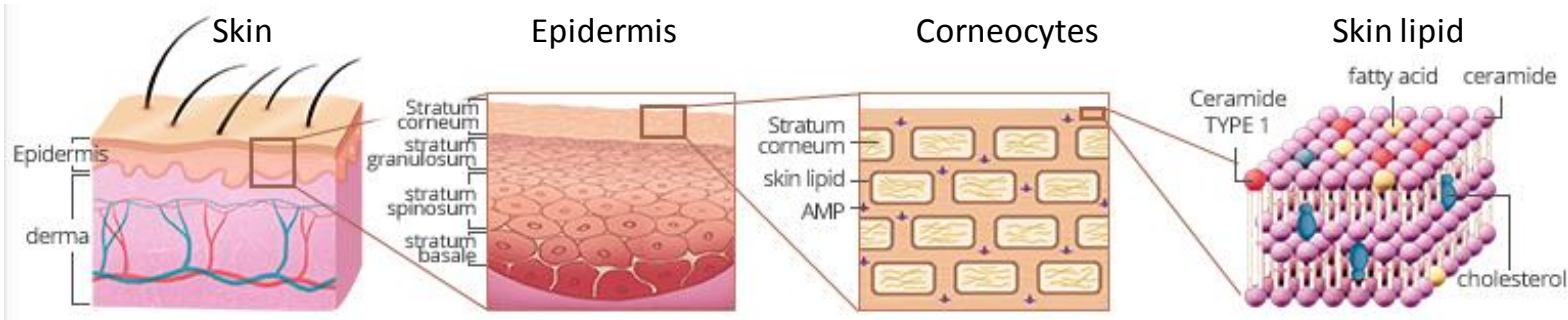

(B)

Passive nicotin patch

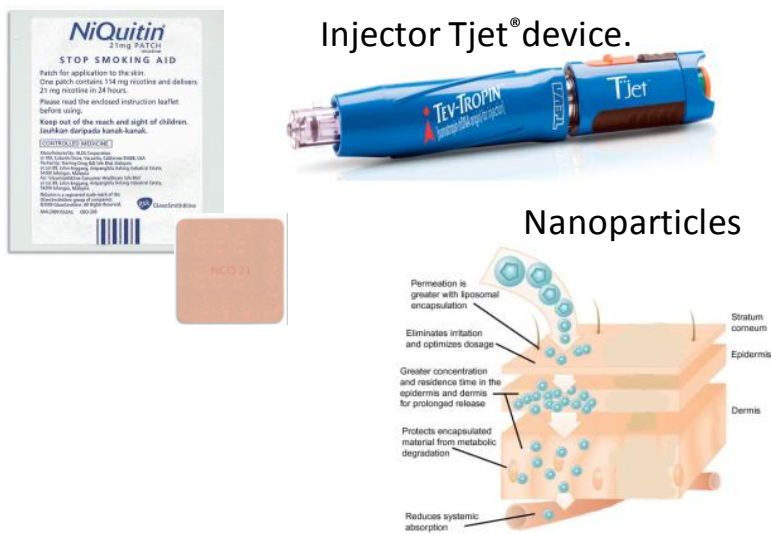

lontophoretic delivery systems (e. g.

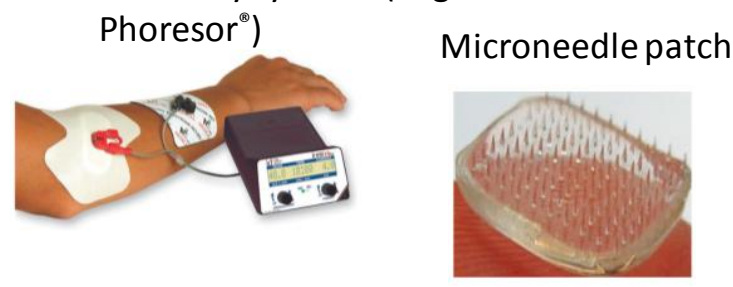

Figure 1: (A) The skin: composed of the outermost layer, epidermis, derma and the subcutaneous later. The epidermis is divided into stratum corneum, stratum granulosum, stratum spinosum and stratum basale. The SC is the outer most layer of the epidermis consisting of corneocytes and lipids accumulate like a brick and mortar structures. The skin lipid consists of ceramide, cholesterol, and fatty acid, and has a lamellar structure in which several layers are stacked on, top of one other (http://zeroid.com/main/brand.asp?cate $=272 \&$ Pcate $=267 \&$ Mcate $=269$, Downloaded August 26, 2017); (B) Systemic transdermal drug delivery by different means such as passive, microneedles (http://www.karplab.net/wp-content/uploads/Parasite-Inspired-Adhesive-Patch.jpg,d ownloaded August 26, 2017), nanoparticles, physical means (reprint with permission from Ref. ${ }^{3}$ )

While local cutaneous effects are generally achieved by dissolving or suspending the drug in an appropriate vehicle that is applied topically in the form of creams or ointments, administration of 
systemic therapy via the skin is typically accomplished through the use of skin patches and active modes of delivery (Figure 1B).

\section{FDA-approved drugs for systemic drug delivery via the skin}

Transdermal technologies not only provide benefit for systemic drug delivery, but also for local delivery of dermatological and cosmeceutical products. In contrast to simple topological applications using creams and ornaments, systemic drug delivery via the skin requires administration of larger doses through normal skin. As a result, at the time of writing, about 20 drugs have been FDAapproved for transdermal administration sharing several characteristics such as low molecular weight, lipophilic and relatively low dose administration requirements (Table 1).

Table 1: FDA approved transdermal delivery drugs (reprinted partially from References ${ }^{4,3}$ )

\begin{tabular}{|l|l|l|}
\hline Active principle & Indication & year \\
\hline Scopolamine & Motion thickness & 1979 \\
\hline Nitroglycerin & Angina pectoris & 1981 \\
\hline Clonidine & Hypertension & 1984 \\
\hline Estradiol & Menopausal symptoms & 1986 \\
\hline Fentanyl & Chronic pain & 1990 \\
\hline Nicotine & Smoking cessation & 1991 \\
\hline Testosterone & Testosterone deficiency & 1993 \\
\hline Estradiol/norethidrone & Menopausal symptoms & 1998 \\
\hline Ethinyl estradiol/norelgestromin & Contraception & 2001 \\
\hline Estradiol/levonorgestrel & Menopausal symptoms & 2003 \\
\hline Oxybutynin & Overactive bladder & 2003 \\
\hline Lidocaine with tetracaine & Local dermal analgesia & 2004 \\
\hline Methylphenidate & Hyperactivity disorder & 2006 \\
\hline Selegiline & depressive disorder & 2006 \\
\hline Rotigotine & Parkinson's disease & 2007 \\
\hline Rivastigmine & Dementia & 2007 \\
\hline Diclofenac epolamine & Acute pain & 2007 \\
\hline Granisetron & Chemo-induced emesis & 2008 \\
\hline Capsaicin & Neutropathy pain & 2009 \\
\hline Buprenorphine & Chronic pain & 2010 \\
\hline Influenza-virus vaccine & Influence virus & 2011 \\
\hline
\end{tabular}

To increase the list of therapeutics for transdermal delivery, significant efforts have been expended on the development of new approaches to enhance transdermal delivery. They can be broadly divided into passive and active technologies (Table 2). While the use of chemical skin enhancers (e. g. azone, peptides and more lately ionic liquids) $)^{5-8}$ has allowed in several cases to increase passive diffusion of small therapeutics, significant efforts have been devoted in the last years on the development of particle based $^{9-12}$ and active technologies to modify the barrier properties of the SC. Given the benefits of both passive and active technologies for local and systematic delivery, some of the most important technological advances in these areas are reviewed in this article.

Table 2: Different Technologies for enhancing transdermal drug delivery.

\begin{tabular}{|l|l|l|}
\hline & Technology & Description \\
\hline Passive Strategy & Particulate systems & $\begin{array}{l}\text { liposomes, transfersomes, niosomes, ethosomes } \\
\text { microemulsions, dendrimers, polymeric or lipid }\end{array}$ \\
\hline
\end{tabular}




\begin{tabular}{|c|c|c|}
\hline & & nanoparticles \\
\hline & $\begin{array}{l}\text { Chemical penetration } \\
\text { enhancers }\end{array}$ & Glycols, terpenes \\
\hline \multirow[t]{5}{*}{ Active Strategy } & Sonophoresis & $\begin{array}{l}\text { Ultrasound-mediated cavitation and disruption of } \\
\text { SC }\end{array}$ \\
\hline & Iontophoresis & Application of electrical current \\
\hline & Velocity based devices & Use of high-velocity jet to puncture skin \\
\hline & $\begin{array}{l}\text { Thermal ablation } \\
\text { Electoporation } \\
\text { Radiofrequency ablation }\end{array}$ & $\begin{array}{l}\text { Creation of microchannels in SC } \\
\text { Short high-voltage electrical pulses } \\
\text { Alternative current and frequencies }>10 \mathrm{kHz}\end{array}$ \\
\hline & Microneedles & $\begin{array}{l}\text { Creation of microchannels in the outermost layer of } \\
\text { the epidermis }\end{array}$ \\
\hline
\end{tabular}

\section{Passive technologies}

\subsection{Chemical penetration enhancers}

The use of chemical penetration enhancers (CPEs) facilitates drug permeation across the skin by increasing drug participating into the barrier domains of the SC, increasing drug diffusivity in the barrier domain of the SC or the combination of both. Permeation enhancers are conventionally divided into several groups based on their chemical structures. Some examples are glycols (e.g. propylene gycols), fatty acids (e.g. oleic acid), terpenes (e.g. limonene), surfactants (e.g. Tween 80), pyrroliones (e.g. $N$-methyl pirrolidone) and glycol ethers (e.g. Transcutol). More than 300 substrates have been test stand, some excellent reviews are found on this matter and readers interested are advised to consult these reviews. ${ }^{13-15}$ A common drawback of permeation enhancers is that their efficiency is often closely mimicked by skin irritation due to their mechanism of action, disrupting the ordered SC lipid bilayers or corneocytes structures organization. ${ }^{15-17}$ In addition, this approach fails for the delivery of most macromolecular therapeutics.

\subsection{Nanoparticles (NPs)}

Considerable efforts have been devoted on the transdermal delivery of therapeutics using nanoparticles (NPs), as nanoparticle technologies seem to hold hope of expanding the transdermal market. The transdermal transport of nanoparticles through the SC is believed to occur via two possible routes: along the skin appendages that include hair follicles, pilosebaceous pores and sweat glands pore or through the intercellular routes that exist between corneocytes (bricks) and along the lipid matrix (mortar) (Figure 2). The exact mechanism by which NPs improve transdermal delivery of drugs is still not fully clarified. In general, it is assumed that the NPs augment the permeation of the drugs by increasing their aqueous solubility through disruption of the well-organized structure of skin by interacting with skin lipid and/or protein structures. Small NPs, in particular smaller than $50 \mathrm{~nm}$ in diameter, can in general more easily penetrate the skin resulting in better permeation profiles. ${ }^{18}$ The incorporation of surface functions can further influence transdermal particle delivery.

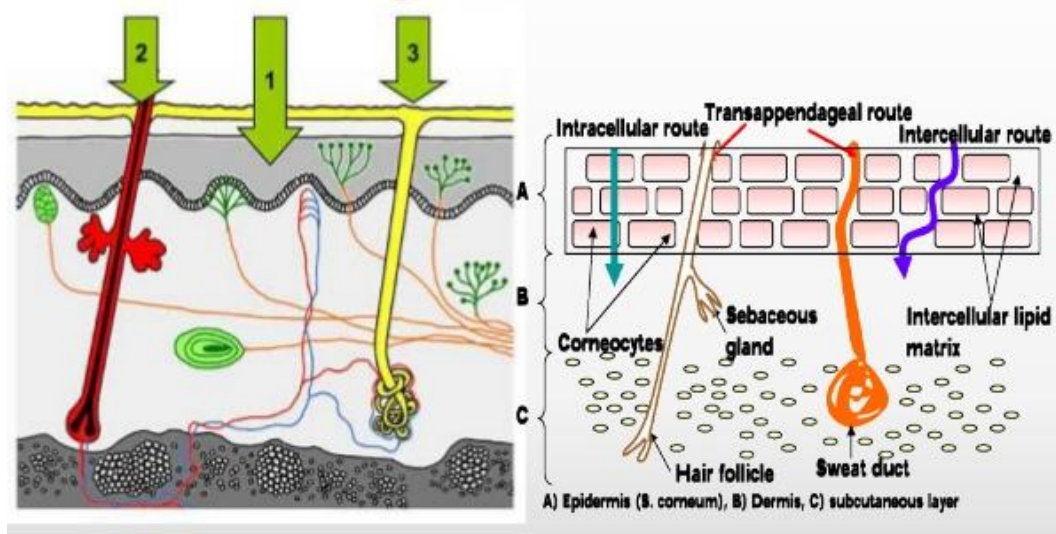


Figure 2. Structure of skin showing routes of nanoparticle penetration: (1) across the intact horny layer, (2) through hair follicles with the associated sebaceous glands, or (3) via the sweat glands (http://www.skin-care-forum.basf.com/en/author-articles/strategies-for-skinpenetration-enhancement/2004/08/12?id=5b9a9164-6148-4d66-bd84-

6df76bd6d111\&mode=Detail. Downloaded August 26, 2017).

\subsubsection{Lipid-based formulations}

\subsubsection{Lipid nanoparticles: Nanoemulsions, solid-lipid nanoparticles, nanostructured lipid} carriers

Lipid-based nanoparticles include a large variety of formulations and were one of the first nanostructures used for transdermal delivery (Figure 3A). Depending on their inner structure, these nanostructures can be classified into lipid nanoparticles/nanoemulsions, solid-lipid nanoparticles (SLNs) and nanostructured lipid carriers (NLCs). In the case of solid lipid nanoparticles (SLNs), the liquid core of lipid nanoparticles is replaced by a lipid solid such as highly-melting point glycerides, which can solubilize lipophilic molecules. They are good candidates for transdermal delivery as they can be prepared in different sizes and it is possible to modify surface polarity in order to improve skin penetration. They are physiologically well tolerated, protect labile drugs from chemical degradation, control the release of the drug due to the solid state of the lipid matrix and can form films over the skin with occlusive properties. High crystalline SLNs have thus been used for physical sun protection due to scattering reflection of the UV radiation by the particles. NLCs consist of a matrix composed of solid and liquid lipids, stabilized by an aqueous surfactant solution. The colloid character makes them an attractive approach to promote drug penetration through SC. Moreover, the small size of NLCs facilitates the contact of encapsulated drugs with the SC and their particular composition in lipids allows the formation of a film on the skin surface, resulting in a local increase in skin hydration. Table 3 summarizes some of the drugs loaded into lipid-based carriers for transdermal delivery

In the case of lipid nanoparticles/nanoemulsions, some examples of drugs delivered through the skin include ketoprofen, aceclofenac etc. ${ }^{19,20}$ An interesting example of lipid nanoparticles is that of cationic ones for topical delivery of plasmid DNA, based on the charge-mediated interaction between the complexes and the skin (Figure 3B). ${ }^{21}$ The surface modification of nanostructured lipid carriers with a peptide containing 11 arginine moieties was found to significantly improve the transport of spantide II (SP) and ketoprofen (KP) to the deeper skin layers, resulting in reduction of inflammation associated with allergic contact dermatitis in mice model. ${ }^{22}$ Due to stability problems associated with these nanostructures, presently little efforts are made to develop lipid nanoparticles/nanoemulsion formulations for transdermal delivery.

The combination of chitosan with SLNs was reported to increase loading with tretinoin (TRE) ${ }^{23}$ as well as its stability. It was found that the SLNs-chitosan-TRE formulation is not toxic to HaCaT cells and exhibits higher antibacterial activity against bacteria involved in acne in contrast with SLNs-TRE. Mendes et al. proposed recently NLCs loaded patches for the co-delivery of olanzapine (OL) and simvastatin (SV). ${ }^{24}$ According to their results, the presence of propylene glycol in the patch led to even higher permeation rate. Methotrexate loaded NLCs-based gel formulations proved to be a new therapeutic approach for the treatment of rheumatoid arthritis. ${ }^{25,}{ }^{26}$ In vivo results showed that this formulation facilitated the transdermal delivery of methotrexate, and decreased the inflammation in rheumatoid arthritis infected animal models (Figure 3C). The potential of ropivacaine-loaded NLCs as a transdermal drug delivery system was investigated by Chen et al. ${ }^{27}$ The NLCs weakened the barrier function of SC, promoting drug permeation through skin without affecting its analgesic effect (Figure 3D). Compared with a controlled group, these particles reduced the writhing response with an inhibition rate of $89.1 \%$. Gomes et al. $^{28}$ showed lately the possibility of using the NLCs for the delivery of minoxidil and finasteride, efficient for hair-loss treatment. 


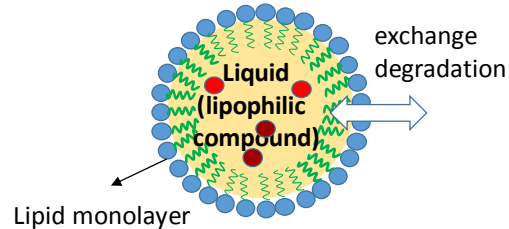

Lipid nanoparticle Nanoemulsion

Lipid monolayer enclosing a liquid lipid core

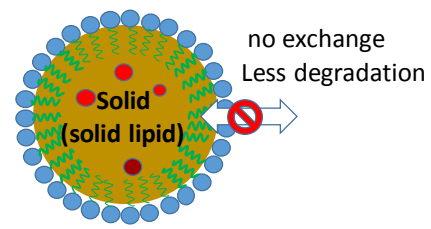

Solid Lipid Nanoparticle (SLN)

Lipid monolayer enclosing a lisolid lipid core

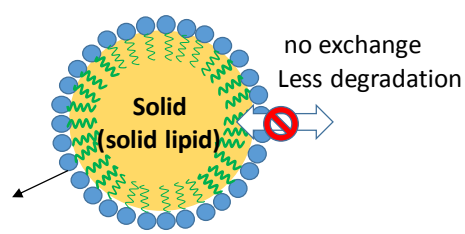

Nanostructured Lipid carrier (NLC)

Lipid monolayer enclosing an imperfect lipid matrix consisting of lipid and solid lipids

(B)
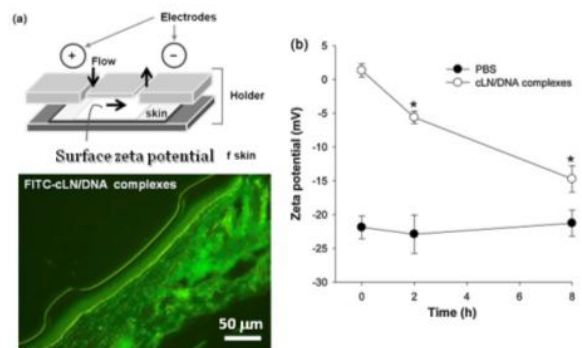

(C)

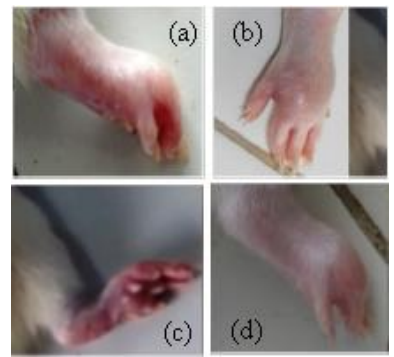

(D)

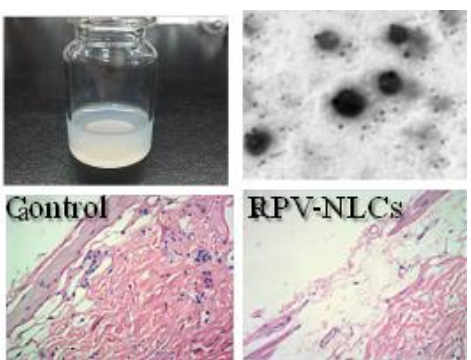

Figure 3: (A) Structures of different lipid-based formulations proposed for transdermal drug delivery, drug is presented as red circle; (B) In vitro skin penetration of cLN/DNA complex: schematic diagram of the experimental setup, zeta potential of the skin surface after treatment with cLN/DNA complexes and the fluorescence images (reprinted with permission from ref. ${ }^{21}$ ); (C) The rat paw images before (a) and after the treatment with (b) gel-(MTX-NLCs), (c) gel-(MTX-NLCs+CE) and (d) gel-MTX (reprinted with permission from ref. ${ }^{25}$ ); (D) The ropivacaine-loaded NLCs as a transdermal delivery system (reprinted with permission from ref. $^{27}$ ).

\subsubsection{Liposomes-Niosomes-Transfersomes-Ethosomes}

Liposomes are among the most studied systems with an excellent review article on this subject by Roberts and co-workers. ${ }^{10}$ Liposomes, spherical vesicles comprising a lipid bilayer with hydrophilic head and hydrophobic tail (Figure 4A), have become one of the preferred nanocarriers for many biomedical applications. ${ }^{29-31}$ Several liposomes-based drugs have been FDA approved as they are nontoxic and generally remain inside the bloodstream for a long time period. The difficulties using liposomes as transdermal drug delivery vehicles is linked to the fact that they tend to adhere to the inside to the skin cell walls, causing the collapse of phospholipid-associated bonds and leaking of the encapsulated drug before reaching deep skin penetration. Examples of skin-based drug delivery based on liposomes include melanin, lidocaine and many others..$^{10,32-34}$

To overcome some of the limitations of liposomes, liposome-like vesicles such as niosomes, transfersomes and ethosomes have been proposed, varying in lipid composition and in the preparation method used. ${ }^{35-37}$ Several extraordinary results regarding the use of niosomes, transfersomes and ethosomes for targeted skin delivery, as well as for enhanced (trans)dermal drug delivery have been reported.
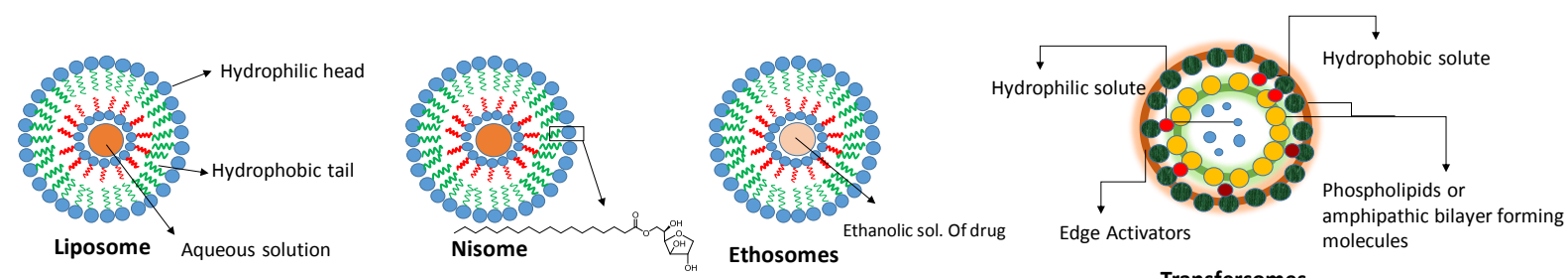

Figure 4: Difference in structures of liposomal based nanoparticles. 
Niosomes $^{38}$ are non-ionic surfactant-based vesicles formed mostly by non-ionic surfactants and cholesterol (Figure 4). They possess good chemical stability during storage and lack many disadvantages associated with liposomes, such as high costs and variable purity of phospholipids. Used in transdermal delivery, niosomes enhance the residence time of the drug in the SC and epidermis and improve their permeation into the deeper layers of the skin. ${ }^{39-41}$ Niosomes have for example proven to be highly efficient for the delivery of minoxidil against hair-loss treatment ${ }^{42}$ or ellagic acid, a chemical that is believed to prevent the growth of cancer cells but is poorly absorbed and quickly eliminated from the body. ${ }^{43} \mathrm{~A}$ different example is that reported by Patel et al. who developed a niosomal gel formulation as transdermal nanocarrier to improve the systemic availability of lopinavir for the treatment of immunodeficiency virus infection. ${ }^{40}$ Transcutaneous immunization has recently emerged as a potential alternative route for the non-invasive delivery of vaccine. The use of niosomes as carriers for topical delivery of vaccines using hepatitis B surface protein as an antigen and of the non-toxic cell-binding B subunit (CTB) of cholera toxin B as an adjuvant have been investigated by Maheshwari et al. ${ }^{36}$ In vitro permeation and skin deposition studies revealed a deeper skin permeation of hepatitis B surface protein-loaded niosomes formulation in comparison with conventional liposomes and plain antigen solution. In addition, topically applied hepatitis B surface protein-loaded niosomes to Balb/c mice showed a strong systemic and mucosal humoral immune response, demonstrating the potential of the antigen encapsulated niosomes/adjuvant formulation as a novel vaccination strategy.

Transfersomes, ${ }^{11}$ trademark registered by the Germany company IDEA AG, are artificial vesicles formed from phospholipids supplemented with surfactants that act as edge activators to provide the morphology of a cell vesicle, but sufficiently deformable to penetrate pores smaller than their own size. Due to their specific structure, transfersomes allow a local and systemic delivery of large macromolecules like proteins, insulin, ${ }^{44,}{ }^{45}$ corticosteroids, ketoprofene, or anticancer drugs. ${ }^{46-53}$ Transfenac, a topical diclofenac transfersomes formulation showed encouraging results in mice, rat and pig models in contrast with a commercial hydrogel to treat moderate pain, signs and symptoms of osteoarthritis or rheumatoid arthritis. Diclofenac associated with ultra-deformable transfersomes has a longer duration of action and reached concentrations 10 times higher in the tissues under the skin compared with the drug delivered from a commercial hydrogel. Moreover, the system was able to penetrate deep into the soft tissue and a sustained release from the carriers deposited into the subcutaneous tissue was observed. ${ }^{54}$ Successful systemic delivery of insulin across intact mice/humans skin barrier together with a significant hypoglycemic response was achieved using an insulin containing transfersomal formulation. ${ }^{47}$ Paul et al. reported that transfersomes can be used to deliver transcutaneously the Gap junction proteins (GJP) for topical immunization. ${ }^{52}$

Finally, ethosomes, soft and malleable vesicle carriers embodying ethanol in relatively high concentrations up to $20-45 \%$, were developed to enhance skin permeation of drugs inside the deep tissue by fluidization of the lipid bilayers of the SC. ${ }^{55}$ An improvement in methotrexate transdermal delivery, which usually shows a low bioavailability and severe gastro-intestinal effects, was obtained using ethosomal formulation. ${ }^{56}$ In addition, the transdermal penetration of testosterone from an ethosomal patch was significantly enhanced compared with a commercial patch. ${ }^{57}$ The results of Dayan et Touitou ${ }^{58}$ indicated that enthosomal formulations containing trihexyphenidyl HCl (THP) may be promising candidates for transdermal delivery of THP as compared with classic liposomes, the ethosomes have shown to exhibit high encapsulation efficiency and a great ability to deliver the THP to the deeper layers of the skin.

Table 3: Lipid based transdermal drug delivery carriers.

\begin{tabular}{|l|l|l|}
\hline Lipid-based formulation & Drug & Ref. \\
\hline \multirow{5}{*}{ Nanoemulsions } & Glycyrrhetic acid & 59 \\
\cline { 2 - 3 } & Ketoprofen & 19 \\
\cline { 2 - 3 } & Aceclofenac & 20 \\
\cline { 2 - 3 } & Celecoxib & 60 \\
\cline { 2 - 3 } & Paclitaxel & 61 \\
\cline { 2 - 3 } & Tolterodine tartrate & 62 \\
\hline
\end{tabular}




\begin{tabular}{|c|c|c|}
\hline & Amlodipine & 63 \\
\hline Cationic LNs & plasmid DNA & 21 \\
\hline \multirow{16}{*}{ Solid lipid nanoparticles (SLNs) } & Quercetin & 64 \\
\hline & Betamethasone-17-valerate & 65 \\
\hline & Tretinoin & $23,66,67$ \\
\hline & Aceclofenac & 68 \\
\hline & Aconitine & 69 \\
\hline & JSH18 & 70 \\
\hline & Morphine & 71 \\
\hline & Diclofenac sodium & 72 \\
\hline & Penciclovir & 73 \\
\hline & Cyclosporin A & 74 \\
\hline & Econazole nitrate & 75,76 \\
\hline & Miconazole nitrate & 77 \\
\hline & all-trans retinoic acid & 78 \\
\hline & Isotretinoin & 79 \\
\hline & Podophyllotoxin & 80 \\
\hline & Vitamin A & $65,81,82$ \\
\hline \multirow{15}{*}{$\begin{array}{l}\text { Nanostructured lipid carriers } \\
\text { (NLCs) }\end{array}$} & Oanzapine and simvastatin & 24 \\
\hline & Methotrexate & 83,84 \\
\hline & Ropivacaine & 85 \\
\hline & Calcipotriol and methotrexate & 86 \\
\hline & Minoxidil and finasteride & 87 \\
\hline & Indomethacin & ${ }^{88}$ \\
\hline & Ketoprofen and naproxen & 89 \\
\hline & Tacrolimus & 90 \\
\hline & Spantide II and ketoprofen & 22 \\
\hline & Flurbiprofen & 91 \\
\hline & Nitrendipine & 92 \\
\hline & 8-MOP, 5-MOP and TMP & 93 \\
\hline & Clotrimazole & 94 \\
\hline & Lidocaine & 95 \\
\hline & Lernoxicam & 96 \\
\hline \multirow{11}{*}{ Liposomes } & Amphotericin B & 97 \\
\hline & Ketoprofen, $\beta$-cyclodextrin & $98-100$ \\
\hline & Tetracaine & 101 \\
\hline & Cyclosporin-A & 102 \\
\hline & Melanin & 33 \\
\hline & Lidocaine & 32,34 \\
\hline & Diclofenac diethylamine & 103 \\
\hline & Bupivacaine & 104 \\
\hline & T4N5 & 105 \\
\hline & Dithranol & 106 \\
\hline & Diclofenac sodium & 107 \\
\hline \multirow[t]{12}{*}{ Transfersomes } & Diclofenac sodium & 54 \\
\hline & Ketoprofen & 46 \\
\hline & Insulin & $44,45,47,48$ \\
\hline & Gap junction proteins & 52 \\
\hline & Hydrocortisone and dexamethasone & 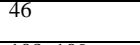 \\
\hline & Oestradiol & 108,109 \\
\hline & Bleomycin & 50,51 \\
\hline & Meloxicam & 110 \\
\hline & Methotrexate & 53 \\
\hline & Dexamethasone & 111 \\
\hline & Sertraline & 112 \\
\hline & Estradiol (with electroporation) & 113 \\
\hline Ethosomes & Methotrexate & 56 \\
\hline
\end{tabular}




\begin{tabular}{|c|c|c|}
\hline & Clotrimazole & 36 \\
\hline & Econazole nitrate & 114 \\
\hline & Acyclovir & 115 \\
\hline & Ammonium glycyrrhizinate & 116 \\
\hline & Testosterone & 57 \\
\hline & Ketotifen & 117 \\
\hline & Ketoprofen & 118 \\
\hline & 5-aminolevulinic acid & 119 \\
\hline & Trihexyphenidyl HCl & 58 \\
\hline & Lopinavir & 40 \\
\hline Niosomes & Acetazolamide & 120 \\
\hline & Minoxidil & 42 \\
\hline & Ellagic acid & 43 \\
\hline & Daunorubicin Hydrochloride & 121 \\
\hline & Nimesulide & 122 \\
\hline & Lidocaine base and hydrochloride & 123 \\
\hline & Terbinafine Hydrochloride & 124 \\
\hline & Capsaicin & 125 \\
\hline & DNA encoding hepatitis B surface antigen (HBsAg) & $36,126,127$ \\
\hline & Enoxacin & 128 \\
\hline Proniosomes & Levonorgestrel & 129 \\
\hline & Estradiol & 130 \\
\hline & Vinpocetine & 131 \\
\hline & Tenoxicam & 132 \\
\hline & Celecoxib & 133 \\
\hline Invasomes & Cyclosporine & 134 \\
\hline & Temoporfin & 135,136 \\
\hline & Ferulic acid & 137 \\
\hline & Idebenone and azelaic acid & 138 \\
\hline & Olmesartan & 139 \\
\hline & Isradipine & 140 \\
\hline
\end{tabular}

8-MOP: 8-methoxypsoralen; 5-MOP: 5-methoxypsoralen; TMP: 4,5,8-trimethylpsoralen; JSH18: 6-methyl-3phenethyl-3,4-dihydro-1H-quinazoline-2-thione;

\subsubsection{Dendrimers and micellar nanoparticles}

Dendrimers, repetitively branched molecules present a promising new approach for transdermal drug delivery (Table 4) ${ }^{141}$ While their biodegradation and inherent cytotoxicity remain an open subject, their unique architecture and chemical composition allow the incorporation of a high drug payload in multiple ways. Generally, the drugs can be encapsulated in the core or conjugated on the surface. Both systems are useful for controlling the release of the therapeutics and protecting them from the surrounding environment. Moreover, their compact structure with a small hydrodynamic radius ensures their diffusion across skin barrier. Dendrimers can also act as skin permeation and solubility enhancers, increasing the transport of lipophilic drugs through the skin. Venuganti and Perumal proposed poly(amidoamine) dendrimer as a new class of skin penetration enhancer. ${ }^{142}$ They showed that the pre-treatment with branched dendritic polymer resulted in higher skin permeation of 5fluorouracil $(5 \mathrm{FU})$ by altering the skin barrier. In addition, the dendrimer surface charge and the vehicle used for $5 \mathrm{FU}$ were found to be very important for the transport of drug molecules across the skin. The higher flux of 5FU was measured when the drug was delivered from isopropyl myristate and the skin was pre-treated with cationic dendrimer, which is expected because the skin is negatively charged at physiological $\mathrm{pH}^{142,}{ }^{143}$ This was similar to the results reported by Wang et al. ${ }^{144}$ that measured a two fold increase in skin permeation of tamsulosin after pre-treating snake skin with a $\mathrm{NH}_{2}$-modified dendrimer. Hegde et al. ${ }^{145}$ reported that the presence of free peptide dendrimers, which act as transdermal permeation enhancer, significantly increased the skin permeation of the drug through disruption of the well-organized structure of skin by NPs. The same group demonstrated the application of chemically conjugated drug-peptide dendrimers in the presence of iontophoresis as a 
topical formulation to enhance the transdermal permeation of the ketoprofen (Figure 5). ${ }^{145} \mathrm{~A}$ comparative study between passive diffusion, sonophoresis- and iontophoresis-assisted penetration of the four peptide dendrimer- drug conjugates (D1-D4) across mouse skin have been performed. The in vitro/in vivo studies revealed that peptide dendrimers and peptide dendrimers/ sonoporesis are not suitable approaches to enhance the permeation of ketoprofen, the plain ketoprofen has been delivered to a greater extent compared with the conjugates and a therapeutically concentration of ketoprofen can be transdermally delivered only with the application of electric current to D2 conjugate. The authors assigned this effect to the presence of positive charge on the dendrimer, which drives the drug molecule into the skin when an electric current is applied. The passive diffusion and the effect of iontophoresis and sonophoresis on the penetration of peptide dendrimers across human skin have been previously investigated. ${ }^{146,}{ }^{147}$ The histopathological evaluations did not show any side effects, the dendrimeric conjugates in combination with iontophoresis/sonophoresis showing a higher dermal safety.

(A)

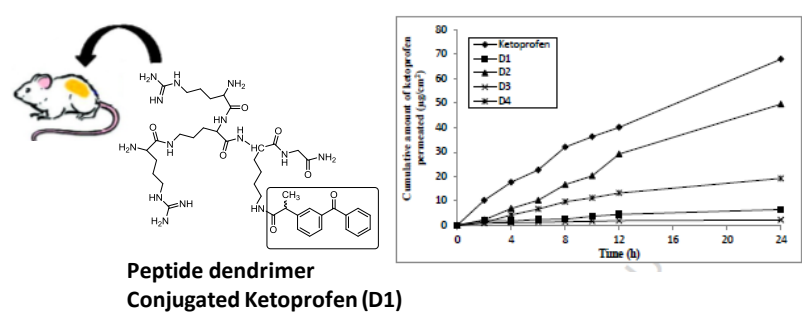

(B)

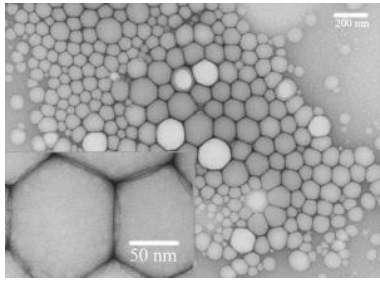

Figure 5: (A) Molecular structures of peptide dendrimeric conjugates of ketoprofen together with in vitro skin permeation profile of ketoprofen and its different dendrimeric conjugates in passive diffusion study; (B) Transmission electron microscopic (TEM) image of a representative micellar nanoparticle formulation manufactured using a high-pressure process. (reprinted with permission from ref. $\left.^{145}\right)$.

Micellar nanoparticle (MNP) (Figure 5B) technology was invented in the mid-1990s ${ }^{148,} 149$ and scientists at Novavax developed and patented MNP technology and subsequently rolled out the first nano-engineered transdermal hormone replacement therapy in 2003 with $17 \beta$-estradiol as active agent. ${ }^{150}$

In 2010, SGN Nanopharma (Titusville, NJ) brought estradiol loaded micellar nanoparticulates (MNP), for treatment of symptoms of menopause onto the market. MNP offers a solution for delivery not only of systemic transdermal products, but also of topical, oral, injectable, and ophthalmic products. Navdeep Jaikaria, SGN's CEO, indicates that MNP gives SGN the ability to reformulate $60 \%$ of all small-molecule drugs. The company also has a platform for delivery of inhaled products and is developing a technology for large-molecule peptides. These peptides must have a stable conformation that withstands the high pressure under which formulations are produced. Jaikaria adds that only GRAS-listed (Generally Recognized As Safe) additives are used. The technology primarily permits delivery of small-molecule drugs, but Jaikaria says that it also will function with small peptides as long as conformation is not an issue. He says that any drug listed as BCS Class 2 (a measure of drug absorption), or that is poorly water-soluble, is a possibility for delivery.

\subsubsection{Polymeric nanoparticles}

Considerable research has been directed towards developing polymeric nanoparticles for drug delivery, but have also received some interest as transdermal drug carrier with chitosan-based nanostructures the most widely employed (Table 4). ${ }^{12,151-157}$ This is mainly due to the ideal properties of this cationic polysaccharide such as low cost, biodegradability, biocompatibility as well as bio adhesion and permeability-enhancing properties linked to its positive charge. Chitosan-ibuprofengellan nanogels were proposed by Abioye et al. for the controlled delivery of ibuprofen. ${ }^{151}$ Interaction 
between ibuprofen and chitosan produced spherical nanoconjugates with remarkable decrease in size of ibuprofen from 4580 to $14.15 \mathrm{~nm}$. These nanostructures showed a skin enhanced penetration of ibuprofen by a factor of 4 compared to free ibuprofen. Biodegradable nanoparticles composed of chitosan and poly-L- $\gamma$-glutamic acid were prepared by Lee et al. by an ionic-gelation method for transdermal DNA delivery using a low-pressure gene gun (Figure 6A). ${ }^{158}$ Aceclofenac-loaded chitosan-egg albumin nanoparticles prepared through the heat coagulation method were proposed by Jana et al. ${ }^{154}$ These nanostructures showed highest drug entrapment $(96.32 \pm 1.52 \%), 352.90 \mathrm{~nm}$ average particle diameter and $-22.10 \mathrm{mV}$ zeta potential. These particles were in the following used to prepare a Carbopol 940 gel for transdermal application. The prepared gel exhibited sustained ex vivo permeation of aceclofenac over $8 \mathrm{~h}$ through excised mouse skin. Physically cross-linked chitosan hydrogels were proposed as topical vehicle for hydrophilic groups such as propranolol hydrochloride, a non-selective b-adrenergic blocking agent widely used in the treatment of hypertension and other cardiovascular disorders. ${ }^{153}$

TAT peptide modified chitosan based polymeric liposomes with cholesterol for improving transdermal delivery of local anesthetic lidocaine hydrochloride was reported by Wang et al. ${ }^{157}$ and showed that in contrast to normal liposomes, these particles were small in diameter $(154.7 \mathrm{~nm})$, showed high encapsulation efficiency and had 4.17 times higher transdermal flux when compared to the free drug. Cyclodextrin modified chitosan was proposed by Khalil for the encapsulation of warfarin for transdermal delivery. The particles had spherical shape of $35 \mathrm{~nm}$ in diameter with narrow size distribution and $94 \%$ encapsulation efficiency. Permeation studies suggested a controlled and constant warfarin delivery. ${ }^{155}$ Next to chitosan, dextran-capped cellulose acetate phthalate based nanostructures have proven to be effective for stunning the skin penetration of model permeants, such as 5Fluorouracil (5-FU), antipyrine and indomethacin. ${ }^{158}$

(A)

chitosan/poly- $\gamma$-glutamic acid/DNA

(b)

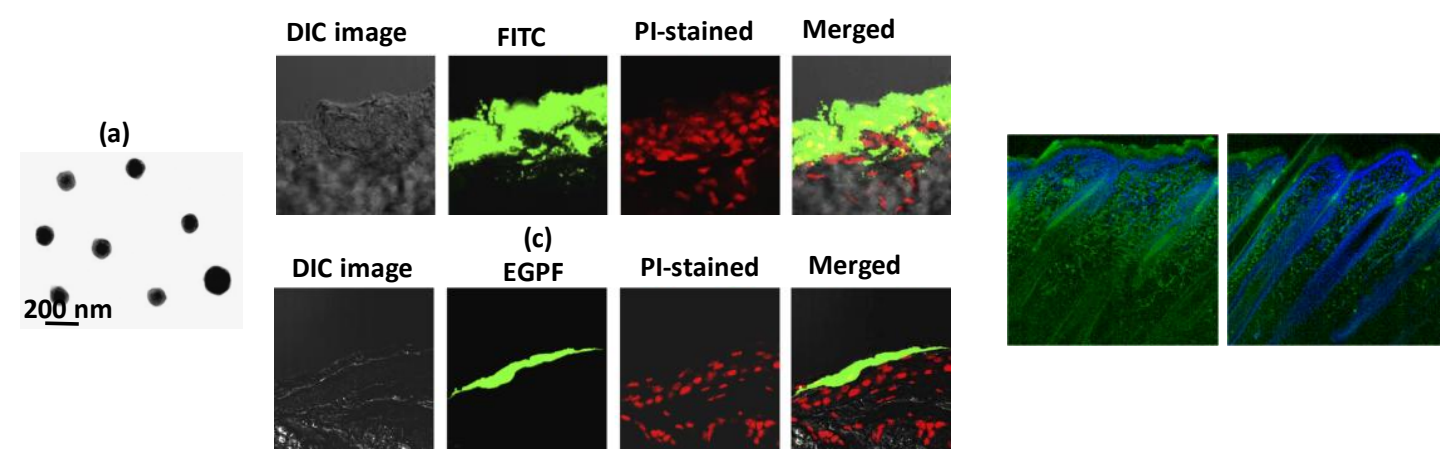

Figure 6: (A) (a) TEM micrograph of chitosan/poly- $\gamma$-glutamic acid/DNA; (b) Fluorescence images taken by an inverted confocal laser scanning microscope after 3D reconstruction of the cross-section of mouse skins after bombardment by FITC-labeled chitosan/poly- $\gamma$-glutamic acid/A using a lowpressure gene gun; (c) EGFP expression after bombardment by chitosan/poly-L- $\gamma$-glutamic acid/A low-pressure gene gun; (b) fluorescence images of the cross-section of mouse skins. CS: chitosan; gPGA: poly-g-glutamic acid; (reprinted with permission from ref. ${ }^{158}$ ); (B) Confocal laser scanning microscopy images of a cross-section of an albino Hartley guinea pig skin where rubrene-loaded nanoparticles were applied for $12 \mathrm{~h}$. (reprinted with permission from ref. ${ }^{159}$ ).

The most widely used polymers are however from synthetic polymers. Natural polymers vary in purity and often lack the batch-to-batch consistency, making it hard to obtain reproducible particles and controlled release patterns of the encapsulated drug. Commonly used synthetic polymers include biodegradable aliphatic polyesters such as polylactides, poly(lactide-co-glycolide (PLGA) copolymers and poly( $\varepsilon$-carprolactone) as well as no degradable polymers such as polyacrylate, poly(methyl methacrylate) or polystyrene. ${ }^{9,12}$ Shim et al. ${ }^{159}$ investigated recently the effect of hydrodynamic size of 
self-assembled poly( $\varepsilon$-caprolactone)-block-poly(ethyleneglycol) NPs on minoxidil skin penetration. The smaller particles $(40 \mathrm{~nm})$ facilitated greater the transport of monoxidil through the skin into the receptor compartment. Confocal laser scanning microscopy images revealed (Figure 6B) that the monoxidil-nanoparticles mainly penetrate via skin appendages such as hair follicles. Skin permeating nanogels for the cutaneous co-delivery of two anti-inflammatory drugs were proposed by Shah. ${ }^{160}$

Methyl methacrylate copolymers are a broad class of materials used for decades in pharmaceutical coatings for the production of oral drug dosage forms. This class of copolymers has also been exploited to prepare transdermal patches or medicated plasters and patches as well as excipients for film-forming topical sprays, microsponges and nanoparticles. Patches containing this class of copolymers are on the market such as Eudragut, a mixture of dimethylaminoethyl methacrylate, butyl methacrylate and methyl methacrylate. While mostly used as skin patches using the good adhesion properties to skin, when it comes to drug delivery via PMMA particles the literature is currently limited to the loading of Nile red and the study of its release. ${ }^{161}$

Another area where polymers have found widespread interest is in the development of suitable formulations that can serve as patch matrix for the drug. Polymers such as hydroxypropylmethylcellulose, polyisobutylene and Ucecryl MC808 were investigated by Guyot et al. as transdermal delivery gels of propranolol hydropchloride. ${ }^{162}$ The best release modulation was obtained from Ucecryl matrices. Most studies in the literature have been carried out with solutions, but to hold promise for further applications, gel systems would be more suitable formulations. Poloxamer 407, a polyoxypropylene-polyoxyethylene non-ionic surface-active block co-polymer composed of $70 \%$ ethylene oxide and $30 \%$ of propylene oxide with a molecular weight of $115 \mathrm{kDa}$, shows reversible thermal gelation properties, solution at low temperature and gel at room temperature making it ideal for transdermal delivery. ${ }^{163}$ This polymer is also well adapted for proteins loading as the solution can be stored at low temperature. Transdermal insulin delivery form poloxamer gels were reported more than 10 years ago in combination with iontophoresis and chemical enhancers. ${ }^{164}$

Co-delivery of PAMAM dendrimer and indomehacin was proposed by Chauhan et al. ${ }^{165}$ as efficient mean for modulating the barrier properties of the skin and facilitating transdermal delivery of the drug. This was similar to the results reported by Yiyun et al. ${ }^{166}$ that found a $\sim 3$ fold increase in skin penetration of ketoprofen and $\sim 2.5$ fold increase of diflunisal after co-administration of drug-PAMAM dendrimer complex. Borowska et al. ${ }^{167}$ assessed the ability of PAMAM dendrimers G3 and G4 for transdermal delivery of 8-methoxypsoralen resulting in better and deep permeation of the drug.

\subsubsection{Metallic nanoparticles}

Silver $(\mathrm{Ag})$ and gold $(\mathrm{Au})$ based NPs have gained considerable attention as potential transdermal carriers due to their ease of preparation, surface modification and tuning their size. While Au NPs are widely used for biomedical applications ranging from cellular imaging to photodynamic and/or photothermal therapy, little knowledge exists about their potential to penetrate the SC and to diffuse in the deeper region of the skin. It is assumed that the transdermal transport of Au NPs is related with their capacity to interact with the skin lipids, altering the SC through the induction of transient and reversible openings (Figure 7A) ${ }^{168}$ Sonavan et al. ${ }^{169}$ studied the penetration of Au NPs of different sizes $(15,102$ and $198 \mathrm{~nm})$ through rat skin and showed that the Au NPs penetration is facilitated for the smallest Au NPs (Figure 7B). Moreover, in contrast with the larger Au NPs that only reach the epidermis, the $15 \mathrm{~nm}$ particles were found to accumulate in the deeper region of the skin, as can be seen in the TEM images of rat skin after $24 \mathrm{~h}$ (Figure 8B). Larese et al. have further shown that $\mathrm{Ag}$ NPs coated with polyvinylpyrrolidone and metallic ions (i.e. nickel and cobalt) can penetrate into the $\mathrm{SC}$ and pass through the skin. ${ }^{170}$ They observed that the permeation kinetics is linked with the state of the skin, with faster permeation observed with injured skin samples. ${ }^{171,}{ }^{172}$ Labouta et al. ${ }^{173}$ demonstrated that hydrophobic Au NPs are more favorable for skin penetration, but at least $6 \mathrm{~h}$ of incubation were required for significant penetration. The effect of charge, shape and functionality of Au NPs on penetration through mouse and human skin was the focus of a study by Fernandes et al. ${ }^{174}$ Their data showed that positively charged Au NPs have 2-6 times higher skin penetration rate compared to their negatively charged counterparts and that rod-shaped Au NPs penetrate the skin in large numbers than spheres. Deep skin penetration could be achieved through peptide coating. 
Extensive studies on the skin permeation properties of PEG and PEG-oleylamine modified Au NPs have been undertaken by Tsai group ${ }^{175}$ and revealed that PEG and PEG-oleylamine act as chemical enhancers, significantly increasing the Au NPs deposition in the deeper layer subcutaneous adipose tissue (Figure 8C). Huang and co-workers ${ }^{168}$ found that co-administration of proteins such as HRP-45 $\mathrm{kDa}$ and $\beta$-gal-460 kDa with $5 \mathrm{~nm}$ Au-NPs can mediate the protein transport across the skin barrier.

Kim et al. ${ }^{176}$ proposed soft block copolymer micelles containing a phase change material (lauric acid) and $\mathrm{Au}$ NPs in the core as a promising carrier for non-invasive transdermal delivery of drugs. The photothermal effect of the Au NPs encapsulated in block copolymer under visible light irradiation $(520-530 \mathrm{~nm}, 30 \mathrm{~mW} \mathrm{~cm}$ ) together with the integration of a temperature sensitive material such as lauric acid proved to be effective for controlled release of indomethacin from these nanostructures through the skin. Moreover, the in vitro studies using Franz diffusion cells and in vivo experiments on Albino guinea pigs proved that the hybrid systems ensure a deeper penetration of the indomethacin after 10 min of irradiation treatment without inducing thermal damage of the skin.

Mandal et al. ${ }^{177}$ proposed a biocompatible and biodegradable cross linked nanocomposite hydrogel using carboxymethyl cellulose (CMC), methacrylic acid, ethylene glycol dimethacrylate and Au NPs (cl-CMC-pMAc/Au NPs) as a transdermal drug carrier. In vitro release of diltiazem hydrochloride (DHL) and diclofenac sodium (DFS) proved that this nanocomposite exhibits a sustained release behavior.

(A)

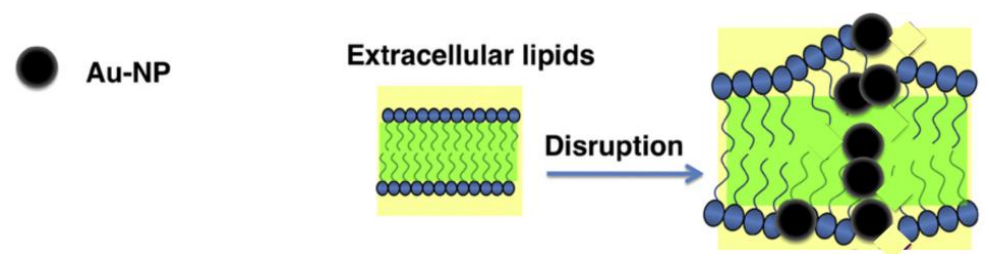

(B)
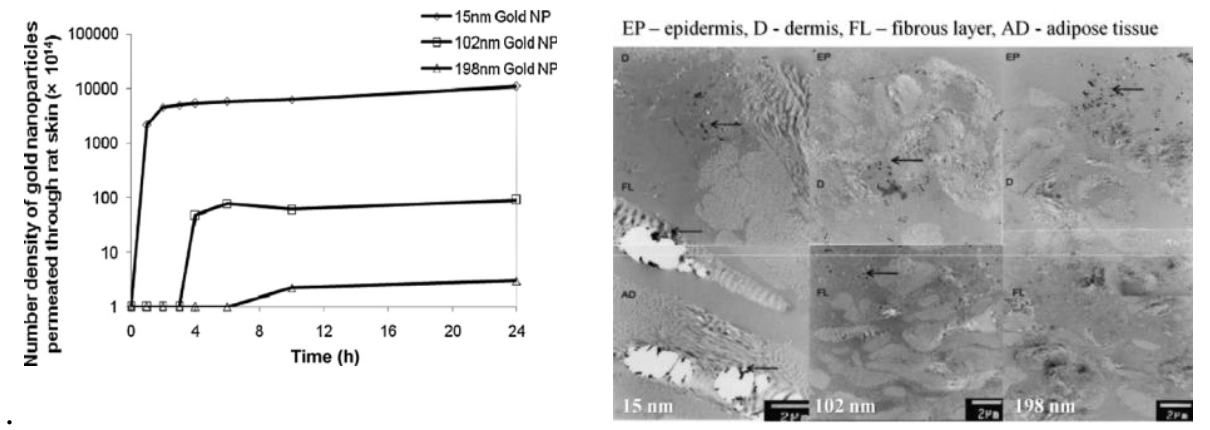

(C)
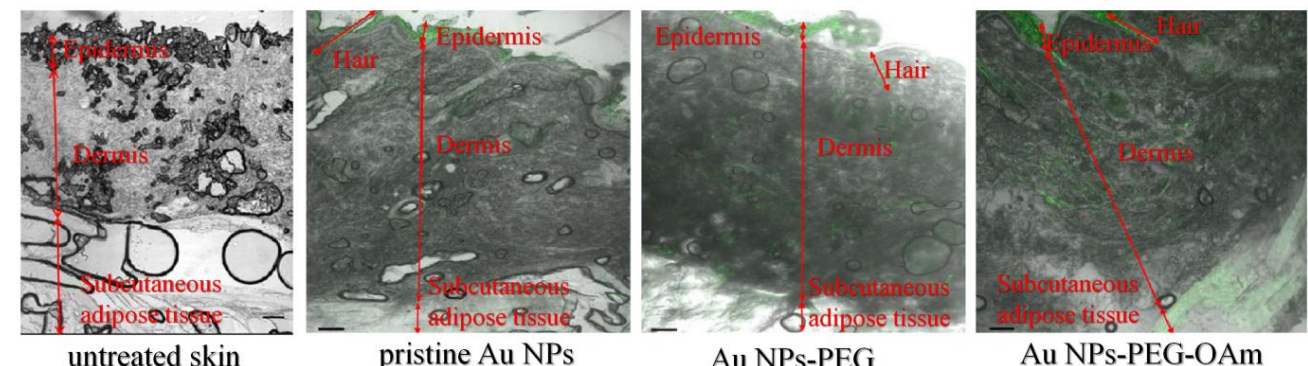

Figure 7. The ability of different sized and functionalized gold nanoparticles (Au NPs) to penetrate the skin barrier and migrate into the deeper layers. (A) Schematic sketch of Au NPs migration across SC (reprinted with permission from ref. ${ }^{168}$ ); (B) Density number of Au NPs permeated through rat skin at different time intervals (left) and TEM images of rat skin after $24 \mathrm{~h}$ (left) (reprinted with permission 
from ref. $\left.{ }^{169}\right)$; (C) CLSM images of different skin layers $24 \mathrm{~h}$ after application of different Au NPs (reprinted with permission from ref. ${ }^{175}$ ).

\subsubsection{Other particles}

There is still little known about the potential application of superparamagnetic iron-oxide nanoparticles (SPION) in transdermal drug delivery. One of the first reports on superparamagnetic particles for transdermal delivery is that of Moritake et al. ${ }^{178}$ in 2007. Epirubicin modified SPIONs were lately proposed for the transdermal administration for tumor treatment. ${ }^{179}$ EPI modified SPIONs demonstrated good inhibition of WM266 cell proliferation and inhibitory effect on tumor proliferation. In vivo transdermal studies demonstrated that the nanoparticles can penetrate deep into the skin when driven by an external magnetic field. This magnetic-field assisted SPION transdermal vector can circumvent the SC via follicular pathways and might have great potential for transdermal therapy of skin cancer (Figure 8A). The utility of hollow copper sulfide nanoparticle (HCuS NPs) for the delivery of human growth hormones was reported by $\mathrm{Lu}$ and co-workers. ${ }^{180}$ It is based on the disruption of the skin using the photothermal properties of the particles (Figure 9B). Photothermal ablation-enhanced transdermal drug delivery using drug-loaded HCuS NPs increased considerably skin permeability of macromolecules such as human growth hormone, offering compelling opportunities for peptide and protein drug delivery.

(A)

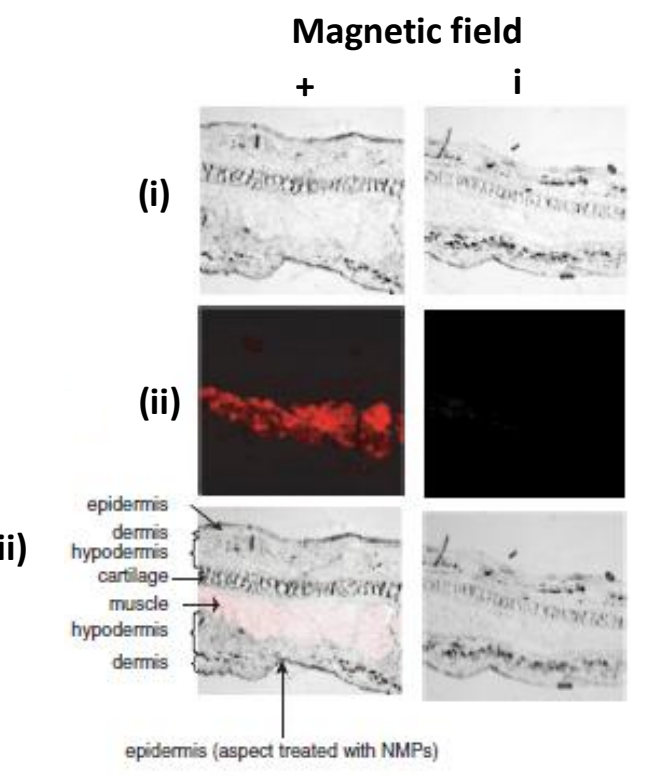

(B)

(a)

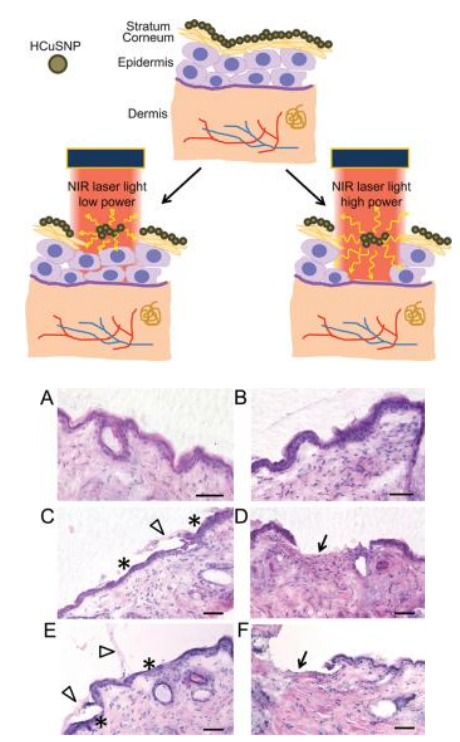

Figure 8. (A) Differential interference contrast images and rhodamine fluorescence images as well as merged images using magnetic nanoparticles in the presence and absence of an external magnetic field ; (B) (a) Hallow CuS nanoparticle mediated photothermal ablation of skin; (b) Images of stained skin sections treated with CuS gel only (i), laser only $\left(2.6 \mathrm{~W} \mathrm{~cm}^{-2}\right)$ (ii), $\mathrm{CuS}$ gel +laser $\left(1.3 \mathrm{~W} \mathrm{~cm}^{-2}\right)$ (iii), $\mathrm{CuS}$ gel +laser $\left(2.6 \mathrm{~W} \mathrm{~cm}^{-2}\right)$ (iv), CuS solution +laser $\left(2.6 \mathrm{~W} \mathrm{~cm}^{-2}\right)$, *: epidermis without SC, arrowhead: SC layer stripped from epidmermis, arrows: dermis with removal of both SC and viable epidermis (reprint with permission from Ref. ${ }^{180}$ ).

Table 4: Summary of other than lipid-based nanoparticles for transdermal delivery of different drugs.

\begin{tabular}{|l|l|l|}
\hline Particles & \multicolumn{1}{|c|}{ Drug } & \multicolumn{1}{c|}{ Ref. } \\
\hline \multirow{3}{*}{ Dendrimers } & 5-fluorouracil & 142,143 \\
\cline { 2 - 3 } & indomethacin & 165 \\
\cline { 2 - 3 } & tamsulosin & 144 \\
\hline
\end{tabular}




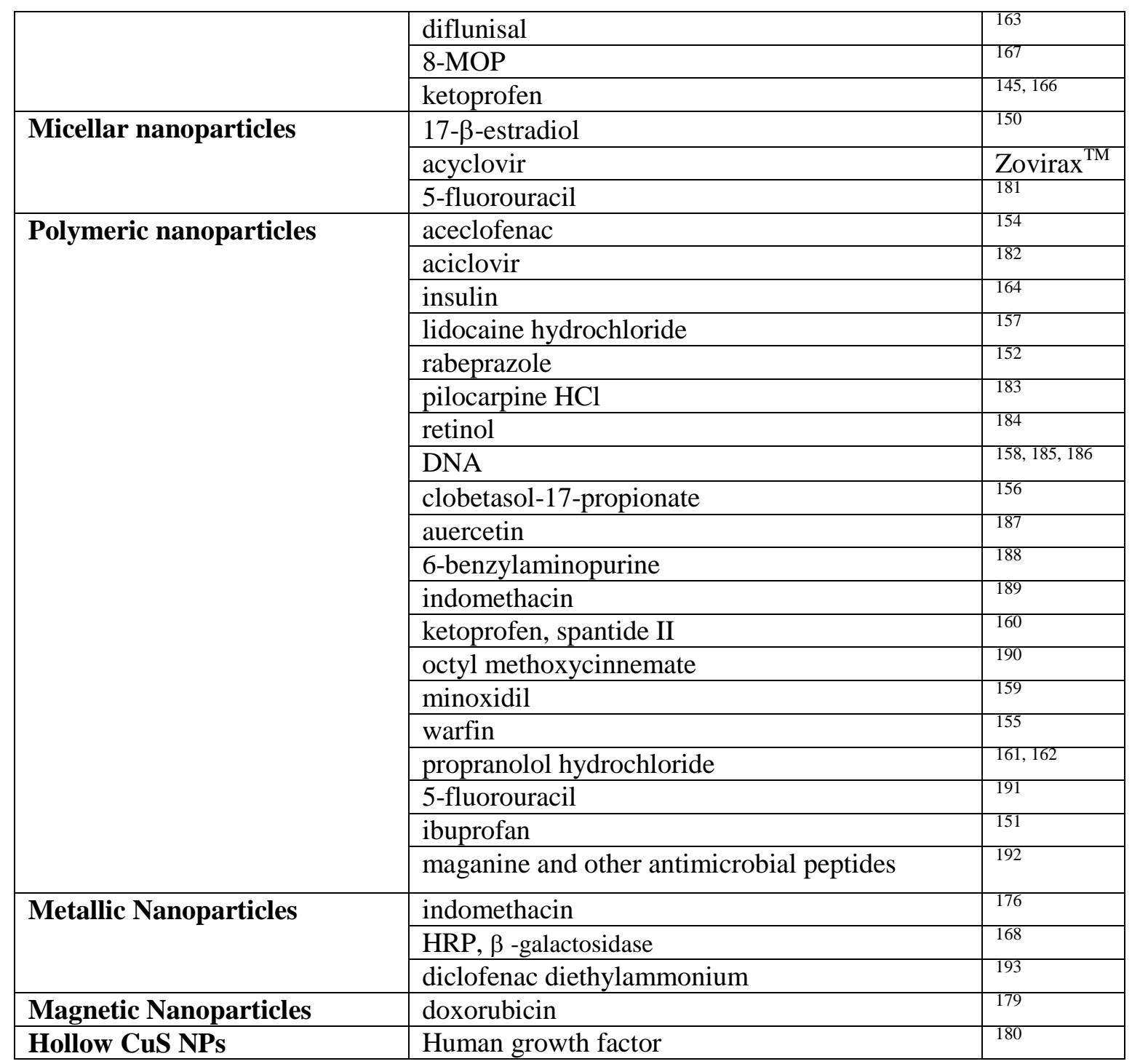

\section{Active technologies (physical methods)}

Some of the limitations associated with passive transdermal technologies has prompted the search for alternative strategies. The active modes for skin permeabilisation are mostly based on external physical triggers such as ultrasound activation, electrically assisted methods (electroporation and iontophoresis), velocity based devices (power injection, jet injectors), thermal approaches (laser and radio frequency heating) as well as mechanical methodologies such as tape stripping, and the use of microneedles (Figure 9).

The physically based removal of the SC by application of adhesive tapes or cyanoacrylate glue, known as stripping, is probably the oldest method. This approach removes both corneocytes and extracellular lipids, reducing the path length that drugs need to cross.

In addition to this method, velocity based devices, either powder or liquid jet injections, employing high-velocity $(100-200 \mathrm{~m} / \mathrm{s})$ to puncture skin and deliver drugs using a power source such as compressed gas or a spring are rather popular still. Two types of liquid jet injectors are currently commercially available: (i) Single-dose jet injectors and (ii) multi-use-nozzle jet injectors. They are needle free devices capable of delivering electronically controlled doses of medication. Such liquid-jet injectors propel liquid from a nozzle with a diameter from 50 to $360 \mu \mathrm{m}$, much smaller than the outer diameter of a hydrodermic needle being $810 \mu \mathrm{M}$ for a $21 \mathrm{G}$ needle, for example. The major advantage of using needle free devices like this relates to concerns regarding safe needle disposal and injuries. The risk of cross contamination is highly possible and patients have reported pain. ${ }^{194}$ This concept is currently used for the delivery of somatropin, a human growth hormone and commercialized under the 
name Tjet ${ }^{\circledR}$ (Figure 1B). Powder jet injectors have the advantage of delivering solid drugs to the skin, the stability of the formulation is increased and does not need cold storage. The basic design consists of drug loaded compartment containing solid drug formulations. It is thus a well-adapted approach for the delivery of nanoparticle formulations.

(A)

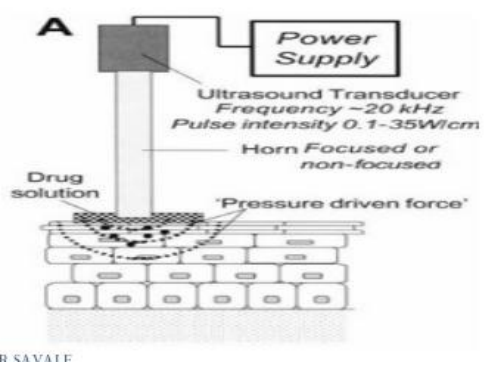

(a)

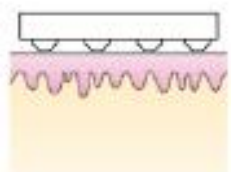

(B)

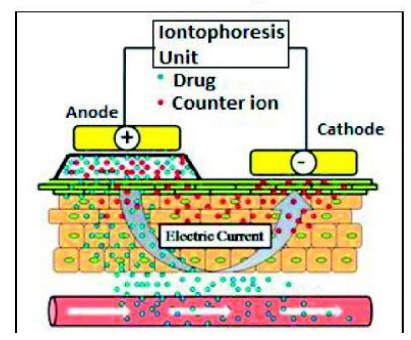

(D)

(b)

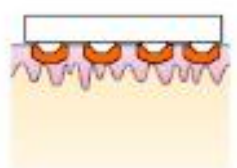

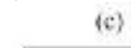

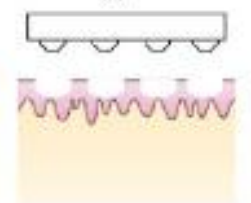

(C)

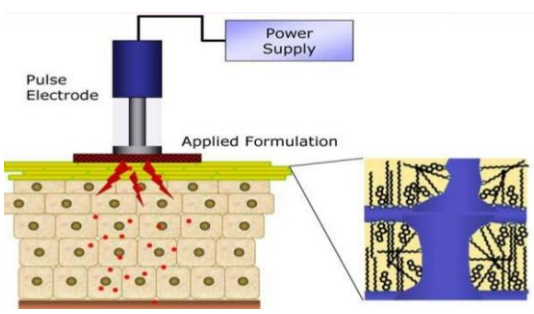

(d)

Figure 9: Active transdermal delivery concepts: (A) Ultrasound based concept (reprint permission from Ref. ${ }^{195}$ ); (B) Iontophoresis concept; (C) Electroporation concept (https://www.slideshare.net/mallikarjuna2055/penetration-enhancers, downloaded 13 October 2017); (D) Skin ablation via heat forming pores in skin (reprint with permission from Ref. ${ }^{3}$ )

\subsection{Ultrasound based approaches (Sonophoresis)}

When ultrasound is utilized in a manner that resembles medical imaging, it is not very effective at increasing skin permeability. However, ultrasound administered in the context of heating tissue can be used to increase drug penetration into the skin. The use of low-frequency ultrasound for the transdermal delivery of drugs, referred to as low-frequency sonophoresis, has shown to increase skin permeability to a wide range of therapeutic compounds (Figure 9A). The first ultrasounds device for transdermal application was approved in 2004 by the FDA for the delivery of lidocaine, a local anesthesia. ${ }^{7}{ }^{196}$ However, high-intensity ultrasound causes second-degree burns limiting the delivery of macromolecules. With frequencies $<1 \mathrm{MHz}$, ultrasound can be used to generate bubbles which can mechanically impact the skin, creating submicroscopic defects in SC. Cavitational ultrasound of the skin has been approved as a pretreatment prior to the application of lidocaine as a means of accelerating local anesthesia.

\subsection{Electrical approaches}

\subsubsection{Iontophoresis}

Iontophoretic skin patches use low physiological acceptable electrical currents $\left(0.1-1 \mathrm{~mA} \mathrm{~cm} \mathrm{~cm}^{-2}\right)$ applied for minutes to hours from an externally placed electrode in order to drive the drugs across the SC, primarily via the effect of electrophoresis. The success of iontophoretic technologies requires choosing the right disease area and the right molecule, one that is difficult to deliver by other methods, has poor absorption in the gut, and can benefit from the use of an electric current to increase the speed or rate of delivery. Drugs that require delivery on a daily basis over an extended period of time (e.g., 24 hours per day) may not be ideal for iontophoretic technologies (Figure 9B). Unlike other approaches, several iontophoretic-based skin patches are on the marked for delivery of drugs such as lidoacaine/epinephrine, fentany or most lately a drug against migraine, sumatriptane, known under the commercial name of Zecuity. Zecuity delivers the migraine drug over a four-hour period and at a 
specified rate with low patient-to-patient variability. The microprocessor continuously monitors skin resistance and can adjust the current to deliver predefined doses.

The transdermal transport rate is proportional to the applied constant current enabling enhancement of transdermal dose and control of drug delivery kinetics. The amount of drug delivered is determined by the maximal current applicable before the pain level is reached. This approach is however not adapted to the delivery of larger molecules.

\subsubsection{Electroporation}

In contrast to iontophroretic approaches, electroporation utilizes very short and high voltage (50-500 $\mathrm{V})$ pulses to induce pores in the lipid bilayer of the $\mathrm{SC}$, allowing the diffusion of the drug across the skin (Figure 9C). Properly designed systems can minimize sensation from the pulses and facilitate delivery, especially of hydrophilic and charged molecules into the skin. While small and higher molecular weight drugs can be delivered into the skin, the main drawbacks are the lack of quantitative delivery, cell death with damage of proteins and thus their bioactivity. This approach is only at the research stage with regard to transdermal delivery. Electroporation is currently used only to drive chemotherapeutic agents into superficial skin tumors by applying surface or penetrating electrodes. ${ }^{197}$

\subsection{Microporation}

\subsubsection{Thermal ablation}

In addition to these methods, several approaches based on the microporation of the SC have been reported (Figure 9D). Thermal ablation, based on the selective removal of the SC by localized microsecond heat pulses, has been proposed as a promising mechanism to increase the permeability of the skin's outer barrier layer while sparing deeper living tissue. ${ }^{198,}{ }^{199}$ The creation of local heat leads to cell ablation and transient creation of microchannels or pores typically $50-100 \mu \mathrm{m}$ in diameter. This technology enables the transdermal delivery of a wide range of drugs including macromolecules (e.g. bovine serum albumin). However, the structural changes in the skin might be irreversible. The use of sophisticated laser setups or micro-fabricated devices to eject superheated steam to the skin with integrated electrical charge to heat a few micro-liters of water limits most likely self-administration possibilities.

The topical delivery of methotrexate via the skin using a combination of electroporation and laser treatment was proposed for increasing the permeation of methotrexate (MTX), a highly hydrophilic and high molecular weight ( $\mathrm{MW}=454.56 \mathrm{Da}$ ) agent used for the treatment of human skin diseases such as psoriasis or an immune suppressant in the treatment of rheumatoid arthritis. When taken orally, the uptake of MTX by the gastrointestinal tract is limited and has shown to cause next to nausea and abdominal distress hepatotoxicity and bone marrow suppression. Lee et al. showed that using an erbium:yttrium-aluminium-garnt (Er: YAG) laser at low fluences can safely and painlessly enhance drug absorption by the skin. ${ }^{200-202}$ Using fluorescein isothiocyanate labeled dextran of increasing molecule weight $(4.4,49.4,38$ and $11 \mathrm{kDa})$ in combination with fluorescence microscopy allowed examination the distribution of the drug in the different skin layers, depending on the treatment (Figure 10A).

By combining laser ablation of SC with electroporation, producing transient pores within the lipid bilayers of the SC, that partially contribute for the increase in skin permeability, it was found that the flux of MTX through the skin could be increased partially (Figure 10B). A combination of laser pretreatment and electroporation results in a 5-6.6 fold higher flux of MTX using a combination of $1.4 \mathrm{~J}$ $\mathrm{cm}^{-2}$ and 10 electroporation pulses over transport by laser or electroporation only. With 20 pulses of laser pre-treatment, only a 2.8 -fold increase in flux is observed. It is important to notice that Er: YAG laser at $1.9 \mathrm{~J} \mathrm{~cm}^{-2}$ can totally overcome the barrier function of the skin against MTX. However, the laser at this fluence is not only ablating the SC layer, but also disrupts viable skin. This is not noticed with the lower flux of $1.4 \mathrm{~J} \mathrm{~cm}^{-2}$ insuring the in vivo and clinical safety of the approach. 

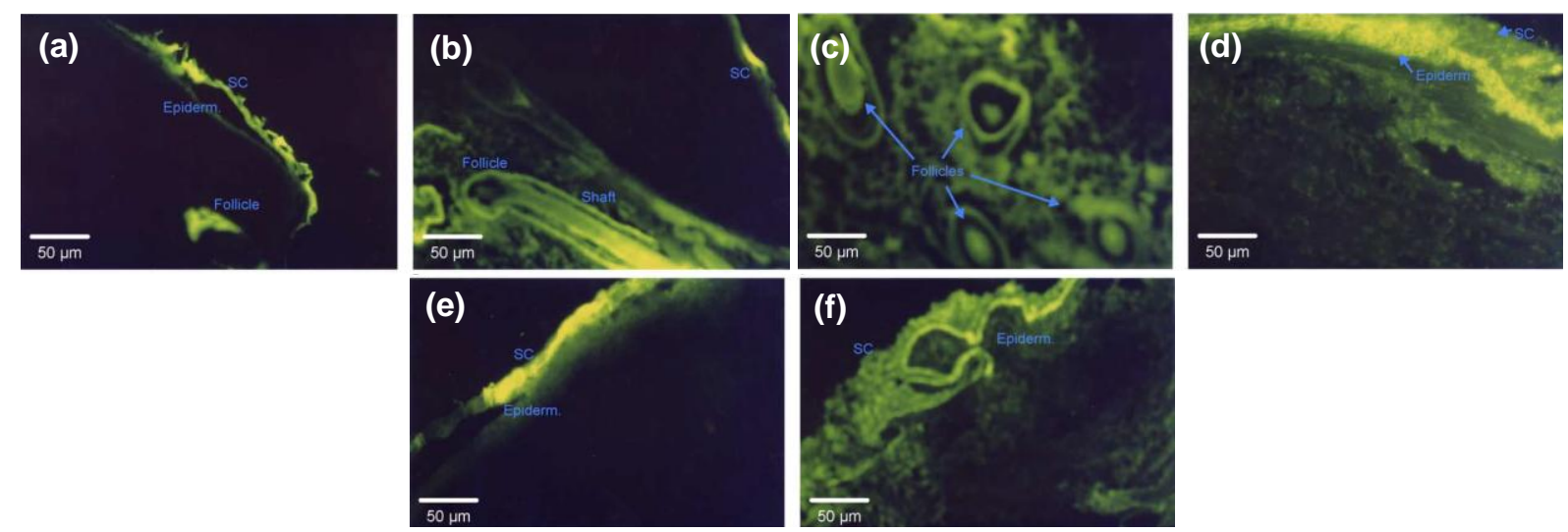

(B)

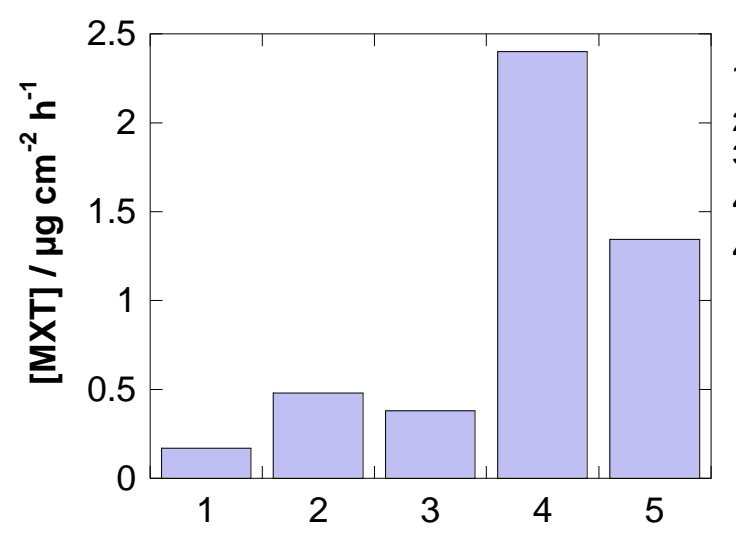

1 passive

2 Laser treatmetn $\left(1.4 \mathrm{~J} \mathrm{~cm}^{-2}\right)$ 3 Electroporation (20 pulses)

4 Laser/Electroporation (1.4J $\mathrm{cm}^{-2} / 10$ pulses)

4 Laser/Electroporation $\left(1.4 \mathrm{~J} \mathrm{~cm}^{-2} / 20\right.$ pulses)

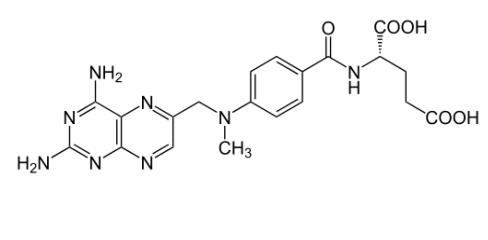

(C)

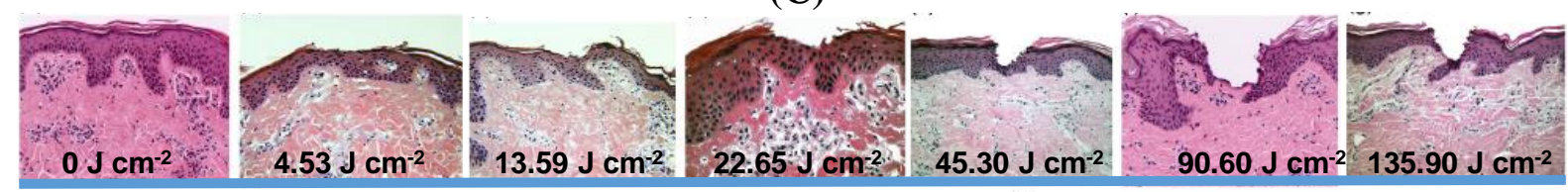

Figure 10: (A) Fluorescence microscopy examination after topical administration of FITC and FITClabeled dextrans via pig skin for $30 \mathrm{~min}$. (a) topical FITC delivery into the skin treated by Er:YAG laser at $1.7 \mathrm{~J} \mathrm{~cm}^{-2}$ in the longitudinal section; (b) FITC delivery into the skin treated by Er:YAG laser at $1.7 \mathrm{~J} \mathrm{~cm}^{-2}$ in the cross-section; (c) FITC-dextran (4.4 kDa) delivery passively; (d) FITC-dextran (4.4 $\mathrm{kDa}$ ) delivery into the skin treated by Er:YAG lasser at $1.7 \mathrm{~J} \mathrm{~cm}^{-2}$ in the longitudinal section; (e) FITCdextran $(38 \mathrm{kDa})$ passive delivery; (f) FITC-dextran $(38 \mathrm{kDa})$ delivery into the skin treated by Er:YAG laser at $1.7 \mathrm{~J} \mathrm{~cm}^{-2}$ in the longitudinal section; (B) in vitro determined MTX flux via skin using passive diffusion, laser treatment, electroporation and a combination with laser and electroporation (reprint with permission of Ref. ${ }^{202}$ ); (C) Haematoxylin/erosin stained histological sections of porcin skin samples: (a) untreated and after painless laser epidermal system P.L.E.A.S.E treatment at different fluences $\left(\mathrm{J} \mathrm{cm}^{-2}\right)$ : (b) 4.53, (c) 13.59, (d) 22.65, 45.3, (f) 90.6, (g) 135.9. together with cumulative lidocaine permeation across P.L. E. A.S. porated skin (reprint permission from Ref. ${ }^{203}$ ).

Kalia and co-workers proposed a painless laser epidermal system (P.L.E.A.S.E.) for enhanced drug delivery through the skin. ${ }^{203-205}$ The P.L.E.A.S.E device is built around an Er: YAG laser that emits light at $2.94 \mu \mathrm{m}$, the principle absorption wavelength for water molecules. Their excitation and explosive evaporation from the epidermis lead to local micropore formation, which reduces risk to the surrounding tissue due to minimal heat transfer. The device uses a specially designed scanning laser to create a user-defined array of micropores in the skin surface where the depth of each micropore is controlled by the fluence. In principle, increasing the number of micropores increases the number of 
transport channels and should therefore increase drug delivery rates. Figure 10C indicates that increasing the laser fluence results in pores with increasing depth, ranging from selective ablation of the SC to penetration into the dermis. Interestingly, transport of lidocaine was shown to be effectively independent of laser fluence and hence pore depth. This suggests that no other major diffusional barriers to transport lidocaid are present after removal of the SC.

The influence of the laser wavelength on the enhancement of drug penetration through the skin was examined by Gomez et al. ${ }^{206}$ in 2008. For these studies, Nd: YAG laser at 355, 532 and $1064 \mathrm{~nm}$ was used. The results indicate that the most energetic photons of UV wavelength are able to induce the SC ablation at lower ablation threshold. Less absorption takes place by NIR radiation on the epidermal level, but penetrates more deeply into the dermis structures. In the visible region, absorption depends on the amount of melanin in the skin. All three wavelengths were effective in enhancing skin permeation of the hydrophilic 5-fluorouracil.

The influence of laser type was assessed by Lee et al. in 2002, who compared Er:YAG, $\mathrm{CO}_{2}$, and ruby laser on the ability to enhance and control skin permeation of 5 -fluorouracil (5-FU). ${ }^{207}$ Skin permeation of 5-FU was moderately promoted by the ruby laser without adversely affecting the viability or structures of the skin. The SC was partially ablated by the Er: YAG laser, resulting in greater enhancement effect on skin permeation of 5-FU. Low energies of $\mathrm{CO}_{2}$ laser did not modulate 5-FU permeation, while higher fluxes $\left(4-7 \mathrm{~J} \mathrm{~cm}^{-2}\right.$ ) result in 36-41-fold increase in 5-FU flux.

\subsubsection{Microneedles}

Microneedles (MN) array, consisting of a plurality of micro-sized tips ranging in length from 25 $2000 \mu \mathrm{m}$ (Figure 11A) offer a highly promising solution for overcoming the barrier that the skin creates to deliver small molecular as well as macromolecular therapeutics such as proteins, peptides and vaccines. ${ }^{208}$ The first concept of MN array for transdermal drug delivery was filed in $1971^{209}$ in a US Patent (Figure $11 \mathbf{B}$ ) and is based on the formation of microholes of about $1 \mu \mathrm{m}$ into the skin through which the drug can pass passively without causing pain. It was however only in 1998 when Henry et al. demonstrated the first proof-of-concept of such a device for enhanced drug delivery into the skin. ${ }^{210}$ To quantitatively assess the ability of MN array to increase transdermal transports, the calcein permeability on human epidermis with and without inserted MN array was investigated. Insertion of MNs into skin was capable of dramatically increasing permeability to calcein. Insertion of the needles for 10 s followed by their removal yielded an almost 10000-fold increase. Insertion for longer times increased even further skin permeability.

(A)
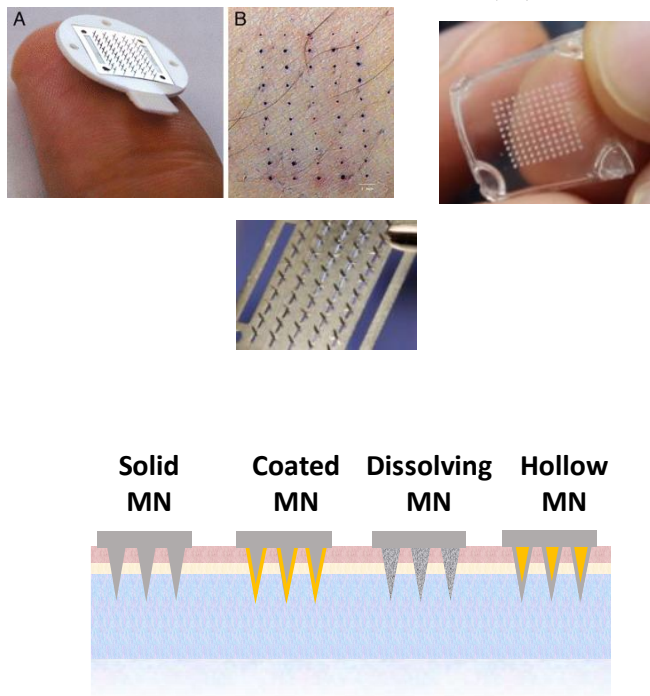

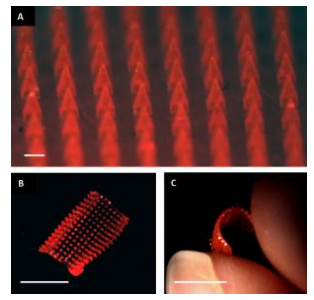

(C)

(B)
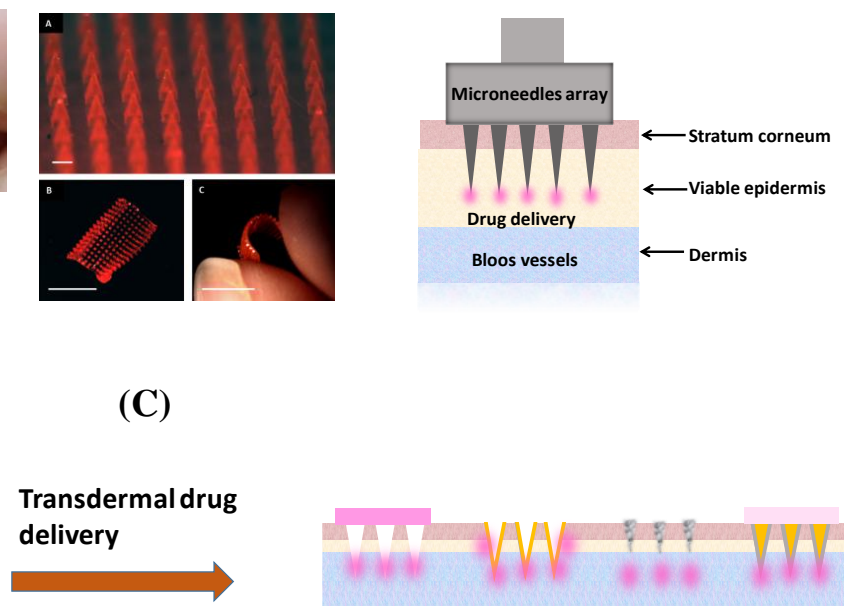

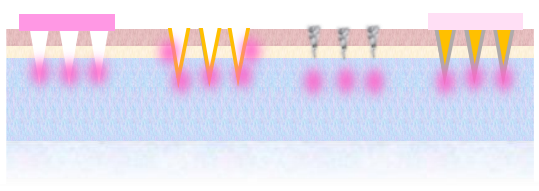

Figure 11: (A) SEM images of different microneedles; (B) Mechanism of action of MN arrays based on the perforation of the SC providing direct access of the drug to the underlying epidermis via 
passive diffusion without reaching blood vessels and nerve fibers located in the dermis;(C) MN design strategies; (a) solid MNs, (b) coated MNS, (c) dissolvable MNS, (d) hollow MNs.

These first solid MN arrays were formed by using simple microfabrication techniques such as deep reactive ion etching of silicon. Since this first seminal work, a large growing body of literature has investigated various microfabrication technologies for $\mathrm{MN}$ array fabrication including numerous materials next to silicon such as metals and various polymers and more lately hydrogels. Typically, there are four different MN arrays designs (Figure 11 C): solid, coated, dissolving and hollow MNs. In the case of the simple solid MNs, the drug reservoir is external in the form of a patch, solution, cream, gel, etc. Coated MN are prepared by coating the drug formulation onto the microstructures. Upon insertion of the array into the skin, the drug will be deposited in the skin following the dissolution of the drug containing material. Dissolving MN arrays create micropores in the skin followed by the dissolution of the MN array upon contact with the skin interstitial fluid and the drug payload is released over time. Dissolving MN array are based on polymers such as chitosan, cellulose, hyaluronic acid. A dissolving MN array based on hyaluronic acid loaded with insulin has been proposed by Yamaoto and coworkers in 2012. ${ }^{211}$ The length of the MNs were $800 \mu \mathrm{m}$ with a base diameter of $160 \mu \mathrm{m}$ and a tip diameter of $40 \mu \mathrm{m}$ ((Figure 12Aa). The skin piercing ability lasted at least for $1 \mathrm{~h}$ even et elevated humidity of $75 \%$, as seen from the SEM images of the MN array before and after application for 30 and $60 \mathrm{~min}$ to rat skin (Figure 12Ab). Insulin could be readily released as the $\mathrm{MN}$ array was completely dissolved within $1 \mathrm{~h}$ after application to the skin (Figure 12Ac). Sustained release of BSA for a least 68 days was reported by Chen using dissolvable chitosan based microneedle patches. ${ }^{212}$ More recently, the development of NIR-responsive polymeric MN arrays have been proposed for drug delivery. ${ }^{213}$ For this, NIR absorbers were integrated into the microneedles by using silica-coated lanthanum hexaboride $\left(\mathrm{LaB}_{6} @ \mathrm{SiO}_{2}\right)$, causing the needles to melt at $50^{\circ} \mathrm{C}$.

The use of silicon or metal MNs has obvious issues with biocompatibility and broken silicon or metal MN can cause skin problems. Coating solid MN is not an easy task and these coatings only deliver a very small drug amount. As in general polymeric microneedles dissolve rather quickly upon contact with water in the skin and results in excessive drug delivery, hydrogel-forming MN might be an alternative. The group of Donnelly et al. described the first hydrogel-forming MN array in 2012 using aqueous blends of polymeric materials, which are poured into silicon micro-molds filled with laser drilled silicon. ${ }^{214}$ Curing the gel at $80{ }^{\circ} \mathrm{C}$ for $24 \mathrm{~h}$ and removing the gel from the mold results in hydrogel microneedle array. Drug loaded patches were attached to the base of the needle array to form an integrated transdermal delivery system (Figure 12Ba). Upon application onto the skin, water diffuses into the needle array, resulting in swelling of the hydrogel and liberation of the drugs without destruction of the array. Different drugs including macromolecules such as BSA and insulin could be permeated with this approach (Figure 13Bb). ${ }^{214}$ Further studies by the same group demonstrated that transdermal drug delivery can be easily controlled by modulating the crosslink density of the hydrogel matrix. This indicates that drug delivery can be tailored on a case-by-case basis to meet the requirements of different drugs with different therapeutic windows. ${ }^{215}$ Super swelling hydrogel microneedles were proposed lately by the same group as an alternative MN system with the advantage of the needles remaining intact even after skin permeation. This system was made from an aqueous blend containing PEG10.000/ $\mathrm{Na}_{2} \mathrm{CO}_{3}$ and Grantrez S-97 and delivered $44 \mathrm{mg}$ of ibuprofen sodium in $24 \mathrm{~h}^{216}$ Microwave-assisted cross-linking of PEG and poly(methyl vinyl ether-alt-maleic acid) was lately proposed by them as an alternative to thermal cross linking, being several times faster but showing the same release profiles for caffeine. ${ }^{217}$ 
(a)

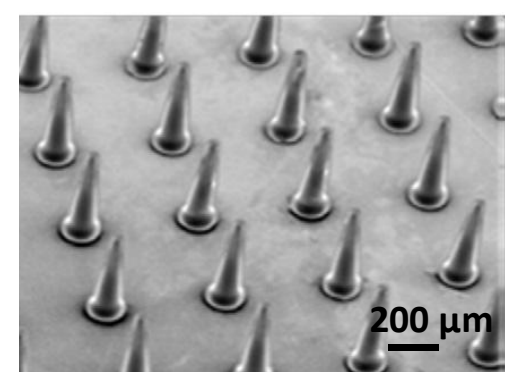

(b)
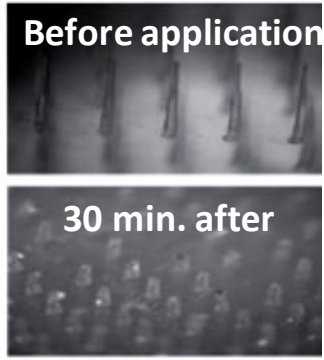

$60 \mathrm{~min}$. after

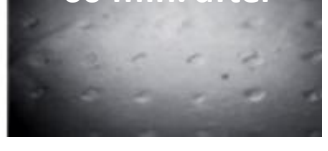

(B)

(a)

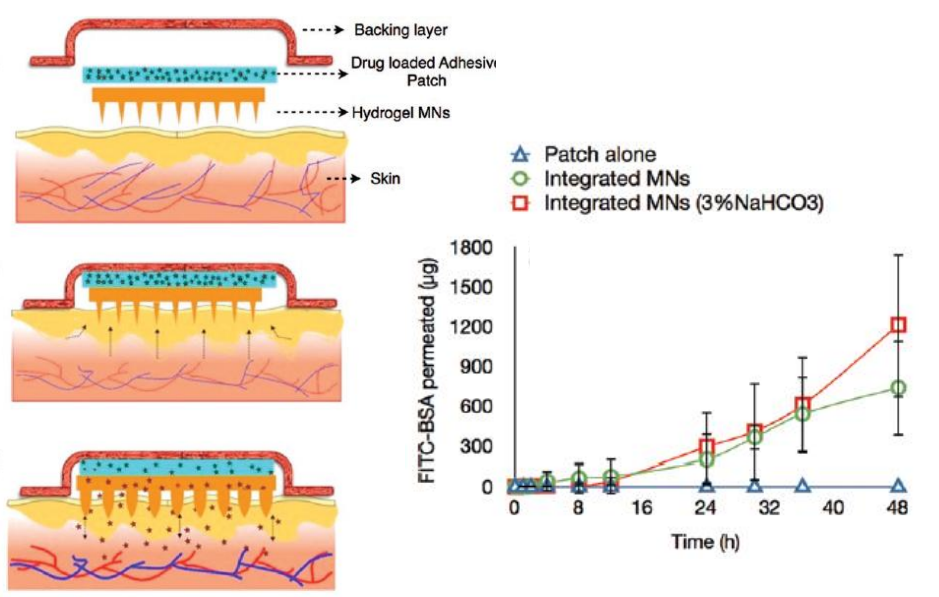

(b)

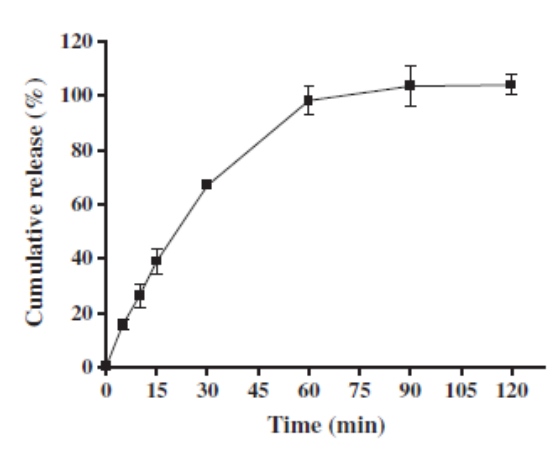

(c)

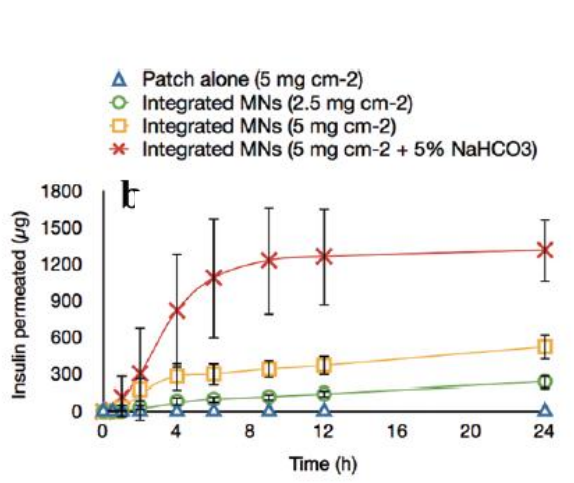

\section{ABAAMAA4}

Figure 12: (A) (a) SEM image of a section of insulin-loaded microneedle array; (b) Micrographs of insulin-loaded dissolvable $\mathrm{MN}$ array before and after an in vivo application on rat skin for 30 and 60 min, (c) in vitro release profile of insulin from insulin-loaded MN arrays in phosphate buffer saline (pH 7.4) (reprint with permission from Ref. ${ }^{211}$ ); (B) (a) Schematic representation of the use of hydrogel-forming polymeric MN for controlled transdermal delivery consisting of a backing layer, a drug-loaded adhesive patch and a solid cross-linked hydrogel MN array. After application of the integrated hydrogel to the skin, diffusion of water into the MN arrays occurs, causing swelling of MN arrays and liberation of drugs into skin, the array remains intact even after removal from the skin; (b) in vitro cumulative permeability results using integrated hydrogel-forming $\mathrm{MN}$ across porcin skin (reprint with permission from Ref. ${ }^{214}$ )

The use of light-responsive hydrogel-forming MN arrays enabling delivery of clinically-relevant amounts of ibuprofen was recently reported using a polymer prepared from 2-hydroxyethel methacrylate (HEMA) and ethylene glycol dimethacrylate (EGDMA) by micromolding, including a light-response 3,5-dimethoxybenzoic conjugate. ${ }^{213}$ Application of an optical UV trigger over a prolonged time of about $160 \mathrm{~h}$ resulted in drug delivery in vitro. ${ }^{218}$

Visible light-triggered on-demand drug release from hybrid hydrogel beads was reported by Kim et $a l^{219}$ Irradiation with visible light resulted in light-induced volume change at body temperature. Spray 
injection method was used to form the beads, consisting of temperature-responsive poly- $N$ isopropylacyrylamide-co-vinyl-2-pyrrolidone) and magnetic particles, which absorb visible light and generate heat. Light-induced volume change of dexamethasone-loaded hybrid beads results in the localized release of drug upon exposure of moderate visible light. ${ }^{218}$ The use of near-infrared responsive composite microneedles was also demonstrated by Chen et al. ${ }^{213}$ Silica-coated lanthrym hexaboride nanostructures were incorporated into polycaprolactone microneedles serving as NIR absorber. Light-to-heat transduction results in melting of the microneedles at $50^{\circ} \mathrm{C}$, increasing the mobility of the polymer chains and enabling drug release from the matrix.

\subsubsection{Photothermal approach}

We have recently added an active approach by proposing photothermal triggered drug release from a skin patch together with enhanced permeation of the therapeutics upon NIR illumination. ${ }^{220,}{ }^{221}$ The skin patch was formed by impregnating reduced graphene oxide ( $\mathrm{rGO}$ ) nanosheets with ondansetron (ODS) and deposited onto a flexible polyimide-based interface, Kapton (Figure 13A). ODS, a selective 5-HT3 receptor antagonist used in the treatment of nausea and vomiting related to cancer chemotherapy, was chosen as a model drug as it seems a well suited transdermal agent with a molecular weight of $293 \mathrm{Da}$, a $\log \mathrm{P}$ value of 2.07 , and a $\mathrm{pK}_{\mathrm{A}}$ of about 7.4. ${ }^{220}$ In vitro release profiles of ODS upon laser irradiation of the patch deposited onto pig skin indicated a correlation between the laser power density and the quantity of ODS crossing the skin (Figure 13A). After a lag time of about $1 \mathrm{~h}$, transdermal ODS delivery was observed when laser power densities of 2 and $5 \mathrm{~W} \mathrm{~cm}^{-2}$ were used. While a constant increase of ODS permeation was observed at $2 \mathrm{~W} \mathrm{~cm}^{-2}$, in the case of $5 \mathrm{~W} \mathrm{~cm}^{-2}$ ODS penetration was more effective in the first $3 \mathrm{~h}$, then stagnated with a reuptake at longer penetration times. The ODS flux across pig skin at $5 \mathrm{~W} \mathrm{~cm}^{-2}$ irradiation was determined to be $J=3.1 \mu \mathrm{g} \mathrm{cm}^{-2} \mathrm{~h}^{-1}$ for the first $3 \mathrm{~h}$ to decrease to $J=1.6 \mu \mathrm{g} \mathrm{cm}^{-2} \mathrm{~h}^{-1}$ thereafter (Figure 13B). The impact of the laserirradiation on the skin structure was in addition taken into account by performing some histological investigations, immediately after the laser activation experiments. Masson's trichrome dye was used for staining as it is commonly used in order to differentiate cells from a specific tissue from cells of other connective tissues by distinguishable colorations of each tissue. Using this dye, keratin and muscle fibers are colored red, collagen and bone blue or green, cytoplasm red or pink, and cell nuclei are brown to black. As can be seen in Figure 14C, no significant histological changes were observed up to a laser power density of $2 \mathrm{~W} \mathrm{~cm}^{-2}$. In the case of $5 \mathrm{~W} \mathrm{~cm}^{-2}$, which resulted in a large enhanced ODS permeation, modification of the skin epidermis structure was noticed. Disruption of the stratum corneum was observed, which is in line with the enhanced transdermal ODS flux.

Addition of penetration enhancers such as Tween 20 into the patch significantly enhanced to $13.2 \pm 1.5$ $\mu \mathrm{g} \mathrm{cm} \mathrm{ch}^{-2}$. With a skin patch of $25 \mathrm{~cm}^{2}$, about $2 \pm 0.2 \mathrm{mg}$ of ODS are delivered every $6 \mathrm{~h}$, a therapeutically correct dose.

This approach was proven to be also valid for the delivery of larger therapeutics such as insulin. ${ }^{221}$ Using insulin loaded photothermal active hydrogels, it was demonstrated that the affinity of insulin inside the hydrogel can by modulated upon NIR irradiation. The temperature rise during the photothermal release does not have any negative consequence on the biological and metabolic activity of insulin as validated by an in vitro assay. The possibility of such a strategy to deliver insulin through the skin has been validated by using porcine skin as a model. These first experiments, which are extremely encouraging, revealed that permeation of insulin is taking place with a flux of $J=.8 \pm 0.2 \mu \mathrm{g} \mathrm{cm}^{-2} \mathrm{~h}^{-1}$ in a relatively short time scale $(0-3 \mathrm{~h})$, significantly higher than passive diffusion. 


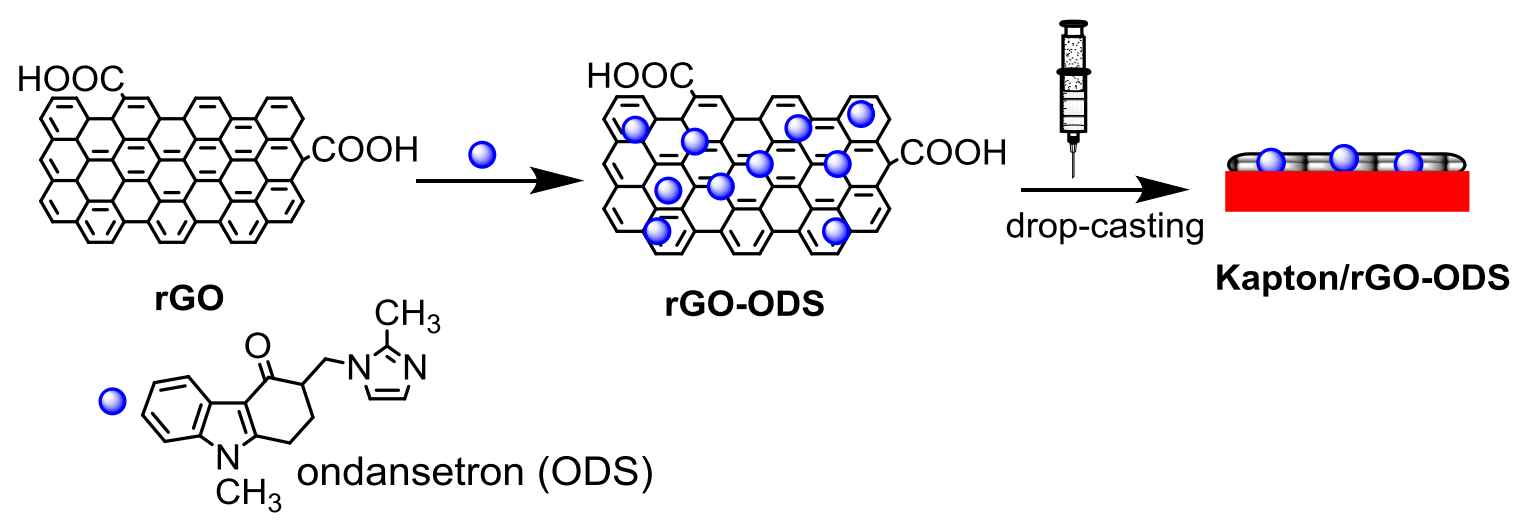

(B)
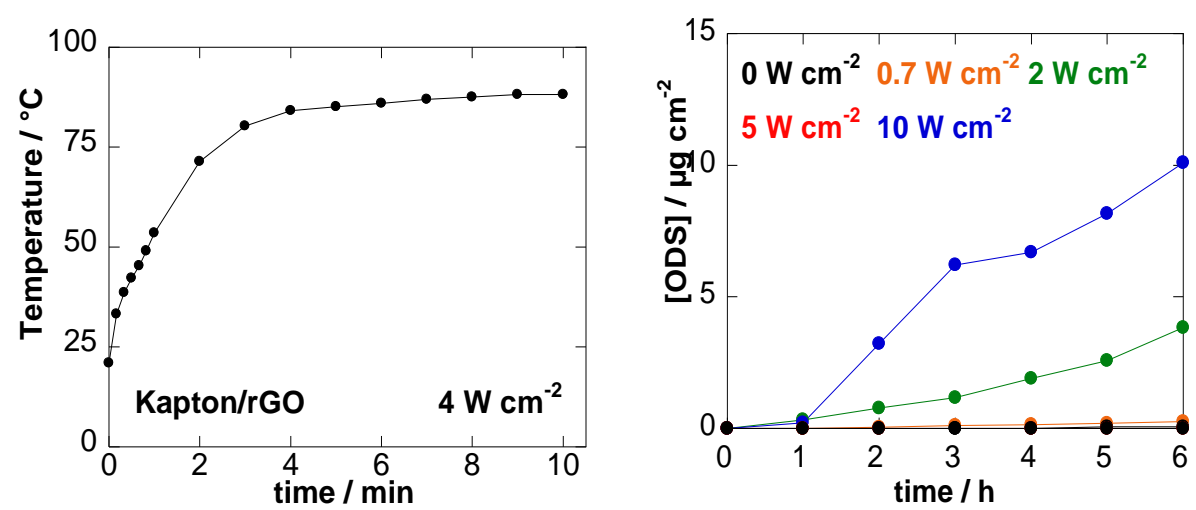

(C)
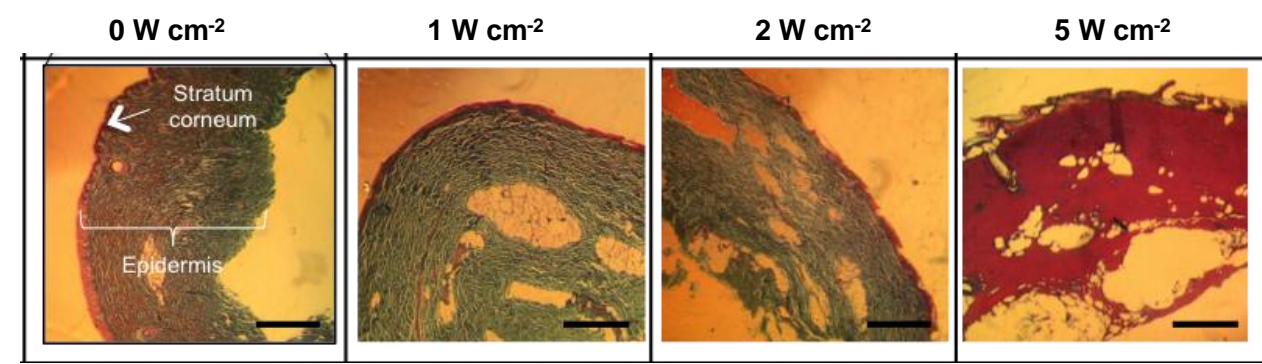

Figure 13: (A) Illustration of the fabrication of a photoactivatable patch for transdermal drug delivery; (B) Photothermal heating capacity of the patch under NIR illumination $(980 \mathrm{~nm})$ for $10 \mathrm{~min}$ at $4 \mathrm{~W}$ $\mathrm{cm}^{-2}$, In vitro permeation profiles of ODS through porcin skin from Kapton/rGO-ODS patches formed by mixing $500 \mu \mathrm{g} \mathrm{mL}^{-1}$ ODS with $1 \mathrm{mg} / \mathrm{mL}$ rGO upon light irradiation for $10 \mathrm{~min}$ using a continuous wave laser at $980 \mathrm{~nm}$ at different laser power densities; (C) Histology of pig ear skin after treatment with different laser power densities at $980 \mathrm{~nm}$ for $10 \mathrm{~min}$. Scale bar $=0.5 \mathrm{~mm}$ (reprint with permission from Refs. ${ }^{220,221}$ )

\section{Conclusion and Perspectives}

In conclusion, transdermal delivery using a combination of approaches has been the focus of study for some time now. Beside the scientific interest and challenge transdermal delivery poses to material scientists, chemists, physicists and nanotechnologies, one has to keep in mind, that the pharmaceutical industry and related companies are mainly interested in transdermal technology for systemic drug delivery because it: (i) avoids problems related to gastrointestinal passage and hepatic first-pass metabolism in which absorption in the liver and the gut wall reduces the amount of drug available for systemic delivery i.e., its bioavailability, (ii) offers a controlled, and continuous delivery of drugs, (iii) provides the option of delivery once or twice weekly, and (iv) facilitates easy termination of the drug. 
From the myriad published studies involving different nanoparticle delivery (Tables 3, 4) and more lately different physical means to overcome the blocking properties of the stratum corneum layer, it is clear that these different approaches are highly promising to not only improving passive transdermal drug delivery, but also to widen the number of drugs which can be transdermally delivered. The methods proposed can reversibly alter the stratum corneum structure thus allowing ingress of hydrophilic or large molecules (eg, chemical enhancers), improve the lipophilicity of small drug molecules (eg, prodrug design), or bypass the stratum corneum via mechanical means (eg, microneedles, jet injection) or an energy source (iontophoresis, electroporation, sonophoresis).

The choice of enhancement method has to be tailored to the specific physicochemical and therapeutic properties of the drug candidate. For example, the application of chemical enhancers can be useful for hydrophilic drug candidates with low molecular weight. When molecular weight poses the main limitation, use of an active technological approach would be more efficient. The development of new patch designs - with active mechanisms for transdermal drug delivery - into commercial products requires balancing enhanced transdermal drug permeation with safety and cost-effectiveness. Table 5 summarizes some of the advantages and disadvantages of the different approaches discussed in this review.

Having understood the positive and negative issues of these different approaches, what is currently then clinical potential of the application of nanoparticles and nanotechnology in transdermal drug delivery? While indeed a wide range of literature has been devoted to passive concepts using different nanoparticles, today there is a move towards "active" transdermal delivery systems that use non- and minimally invasive technologies. Despite several years of efforts, the movement of active technologies into the market has been however slow and only a few have reached the market or been successful. This is mostly due to commercial, technical as well as consumer issues. ${ }^{222}$ The microneedle area is currently one of the most fashionable drug delivery system with the main focus on single-dose administration of vaccines. Sanofi Pasteur brought in 2011 Fluzone Intradermal onto the market, a microneedle-based product for vaccine. Zosano Pharma is currently evaluating MacroFlux microneedle technology for the transdermal delivery of teriparatide, a recombinant form of parathyroid hormone, as an alternative to daily injections for the treatment of severe osteoporosis. For decades another high priority project has been the painless delivery of insulin with a feedback control provided by varying glucose levels. Microneedle technologies intended for delivery of insulin may be combined in the future with blood glucose sampling targeting for a feedback control of drug delivery.

The development of transdermal systems for the delivery of central nervous system and pain-relief medicines is currently part of the research pipeline for several pharmaceutical companies due to ease of application, increased patient compliance and safety of transdermal drug delivery systems. ALZA developed Ionsys, an iontophoretic patch system containing fentanyl, for the short-term management of acute post-operative pain in adult patients requiring opioid analgesia during hospital admission. Vyteris developed LidoSite, a topical iontophoretic patch containing lidocaine hydrochloride and epinephrine to provide fast analgesic effect before venipuncture and dermatological procedures. Zecuity (sumatriptan), a battery-powered iontophoretic patch for the treatment of migraine in adults, developed by NuPathe Inc (Conshohocken, PA), has entered the market.

Considering today's experiences and progress in the transdermal field, it can be concluded that the future of transdermal drug delivery using nanotechnology depends large on progress made with appropriate techniques and approaches to overcome constraints of passive diffusion without compromising skin integrity. It is evident that the transdermal market will largely increase due to patient demand for transdermal dosage forms in conjunction with the adoption of technological approaches that enable the transdermal delivery of a diverse portfolio of therapeutic compounds.

Table 5: Comparison of the different transdermal vectors discussed.

\begin{tabular}{|l|l|l|}
\hline Nanocarrier & Advantage & Disadvantage \\
\hline Liposomes & $\begin{array}{l}\text { Use of natural lipids makes them highly } \\
\text { biocompatible }\end{array}$ & Physical stability issues \\
\hline
\end{tabular}




\begin{tabular}{|c|c|c|}
\hline & Simple manufacturing & $\begin{array}{l}\text { Variable kinetics of distribution } \\
\text { processes }\end{array}$ \\
\hline & High drug loads can be achieved & \\
\hline \multirow[t]{3}{*}{ Dendrimers } & Easily prepared and functionalized & cytotoxic \\
\hline & $\begin{array}{l}\text { Increase bioavailability of drug as they stabilize } \\
\text { drug }\end{array}$ & $\begin{array}{l}\text { Elimination and metabolism can be } \\
\text { a problem }\end{array}$ \\
\hline & Act as solubility enhancers & \\
\hline \multirow{4}{*}{$\begin{array}{l}\text { Lipid-based } \\
\text { particles }\end{array}$} & Low toxicity, biodegradable & Purity of natural phospholipids \\
\hline & Highly flexible, soft & Formulations are costly \\
\hline & Softness, malleability & $\begin{array}{llr}\begin{array}{l}\text { Predisposition } \\
\text { degradation }\end{array} & \text { to } & \text { oxidative } \\
\end{array}$ \\
\hline & Hydrophilic and hydrophobic drugs can be loaded & \\
\hline \multirow[t]{5}{*}{ Nanoparticles } & Can be made of a variety of materials & $\begin{array}{l}\text { Some processes are difficult to scale } \\
\text { up }\end{array}$ \\
\hline & many ways to prepare them & $\begin{array}{l}\text { Reproducibility might be a } \\
\text { limitation for commercialization }\end{array}$ \\
\hline & Rather easy to synthesize and functionalize & $\begin{array}{l}\text { Often not enough toxicological } \\
\text { assessments available }\end{array}$ \\
\hline & Hydrophilic and hydrophobic drugs can be loaded & \\
\hline & Able to avoid the immune system due to their size & \\
\hline \multirow[t]{4}{*}{$\begin{array}{l}\text { Active } \\
\text { approaches }\end{array}$} & Delivery of macromolecular therapeutics & $\begin{array}{l}\text { Partial destruction of skin can lead } \\
\text { to inflammation }\end{array}$ \\
\hline & Delivery of hydrophilic and hydrophobic drugs & \\
\hline & $\begin{array}{l}\text { Often in form of patch designs making the } \\
\text { approaches less prone to cytotoxicity issues }\end{array}$ & \\
\hline & $\begin{array}{l}\text { Integration of controlled triggers possible for on- } \\
\text { demand delivery }\end{array}$ & \\
\hline
\end{tabular}

\section{Acknowledgements}

Financial support from the Centre National de la Recherche Scientifique (CNRS), the University Lille 1, the Hauts-de-France region, the CPER "Photonics for Society", the Agence Nationale de la Recherche (ANR) and the EU union through FLAG-ERA JTC 2015-Graphtivity, and the Marie Sklodowska-Curie action (H2020-MSCA-RISE-2015, PANG-690836) are acknowledged.

\section{References}

1 M. S. Roberts, S. E. Cross and M. A. Pellett, in Dermatological and Transdermal Formulations, ed. K. A. Walters, Marel Dekker, New York, 2002, pp. 89-195.

2 P. M. Elias, J. Invest. Dermatol., 1983, 890, 44S-49S.

3 A. Z. Alkilani, M. T. C. McCrudden and R. F. Donnelly, Pharmaceutics, 2015, 7, 438470;.

4 M. N. Pastore, Y. N. Kalia, M. Horstmann and M. S. Roberts, British J. Pharmacol., 2015, 172, 2179-2209.

5 Y. Chen, Y. G. Shen, X. C. Zhang, W. Yang, M. Ma, S. Liu, M. Zhang and L. P. Wen, Nat. Biotechnol., 2006, 24, 455-460.

6 Y. C. Kim, P. J. Ludovice and M. R. Prausnitz, J. Control. Release, 2007, 122, 375378.

7 I. Som, K. Bhatia and M. Yasir, J. Pharm. Bioallied Sci., 2010, 4, 2-9. 
M. Zakrewsky, K. S. Lovejoy, T. L. Kern, T. E. Miller, V. Le, A. Nagy, A. M. Goumas, R. S. Iyer, R. E. Del Sesto, A. T. Koppisch, D. T. Fox and S. Mitragotri, Proc. Nat. Acad. Sci., 2014, 111, 13313-13318.

9 F. Cilurzo, F. Selmin, C. G. Gennari, L. Montanari and P. Minghetti, Expert Opin. Drug Deliv., 2014, 11, 1033-1045.

10 T. Prow, J. Grice, L. Lin, R. Faye, M. Butler, W. Becker, E. M. T. Wurm, C. Yoong, T. A. Roberston, H. P. Soyer and M. S. Roberts, Adv. Drug Deliv. Rev., 2011, 63, 470491.

11 S. Rai, V. Pandey and G. Rai, Nano Rev. \& Exp., 2017, https://doi.org/10.1080/20022727.20022017.21325708.

12 Z. Zhang, P.-C. Tasi, T. Ramezanli and B. B. Michniak-Kohn, Wiley Interdiscip. Rev. Nanomed. Nanobiotechnol., 2013, 5, 205.

13 B. C. Finnin and T. M. Morgan, J. Pharm. Sci., 1999, 88, 955-958.

14 I. B. Pathan and C. M. Setty, Trop. J. Pharm. Res., 2009, 8, 173-175.

15 A. C. Williams and B. W. Barry, Adv. Drug Deliv. Rev., 2012, 64, 128-137.

16 A. Herman and A. P. Herman, J. Pharm. Pharmacol., 2015, 64, 473-485

17 H. Y. Thon, H. Zhai and H. I. Maibach, Skin Pharmacol. Physiol., 2007, 20, 272-282.

18 A. Kohli and H. Alpar, Int. J. Pharm., 2004, 275, 13-17.

19 B. S. Kim, M. Won, K. M. Lee and C. S. Kim, Drug Deliv., 2008, 15, 465-469.

20 F. Shakeel, S. Baboota, A. Ahuja, J. Ali, M. Aqil and S. Shafiq, AAPS PharmSciTech, 2007, 8, 191-199.

21 S.-E. Jin and C.-K. Kim, Colloids Surf. B, 2014, 116, 582-590.

22 P. P. Shah, P. R. Desai, D. Channer and M. Singh, J. Control. Release, 2012, 161, 735-745.

23 D. M. Ridolfi, P. D. Marcato, G. Z. Justo, L. Cordi, D. Machado and N. Duran, Colloids Surf. B, 2012, 93, 36-40.

24 M. Mendes, S. C. C. Nunes, J. J. Sousa, A. A. C. C. Pais and C. Vitorino, Mol. Pharm., 2017, 14, 2099-2115.

25 N. K. Garg, B. Singh, R. K. Tyagi, G. Sharma and O. P. Katare, Colloids Surf. , B, 2016, 147, 17-24.

26 N. K. Garg, R. K. Tyagi, B. Singh, G. Sharma, P. Nirbhavane, V. Kushwah, S. Jain and O. P. Katare, Int. J. Pharm., 2016, 499, 301-320.

27 H. Chen, Y. Wang, Y. Zhai, G. Zhai, Z. Wang and J. Liu, Colloids Surf. , A, 2015, 465, 130-136.

28 M. J. Gomes, S. Martins, D. Ferreira, M. A. Segundo and S. Reis, Int. J. Nanomed., 2014, 9, 1232-1242.

29 G. Bozzuto and A. Molinari, Int. J. Nanomedicine, 2015, 10, 975-999.

30 B. S. Pattni, V. V. Chupin and V. P. Torchilin, Chem. Rev., 115, 10938-10966.

31 L. Sercombe, T. Veerati, F. Moheimani, S. Y. Wu, A. K. Sood and S. Hua, Front. Pharm., 2015, 6, 286.

32 L. F. Eichenfield, A. Funk, S. Fallon-Friedlander and B. B. Cunningham, Pediatrics, 2002, 109, 1093-1099.

33 M. Sand, F. G. Bechara, D. Sand, P. Altmeyer and K. Hoffmann, Ann. Plastic Surgery, 2007, 58, 551-554.

34 A. Taddio, H. K. Soin, S. Schuh, G. Koren and D. Scolnik, Canadian Med. Assoc. J., 2005, 172, 1691-1695.

35 M. Ashtikar, N. Nagarsekar and A. Fahr, J. Control. Release, 2016, 242, 126-140.

36 C. Maheshwari, R. Pandey, A. Chaurasiya, A. Kumar, D. Selvam, G. Prasad and V. Dixit, Int. Immunopharm., 2011, 11, 1516-1522. 
R. Muzzalupo, L. Tavano, R. Cassano, S. Trombino, T. Ferrarelli and N. Picci, Eur. J. Pharm. Biopharm., 2011, 79, 28-35.

R. Rajera, K. Nagpal, S. K. Singh and D. N. Mishra, Biol. Pharm. Bull., 2011, 34, 945-953.

S. Moghassemi and A. Hadjizadeh, J. Control. Release, 2014, 185, 22-36.

K. K. Patel, P. Kumar and H. P. Thakkar, AAPS PharmSciTech, 2012, 13, 1502-1510.

I. F. Uchegbu and A. T. Florence, Adv. Colloid Interface Sci., 1995, 58, 1-55.

P. Balakrishnan, S. Shanmugam, W. S. Lee, W. M. Lee, J. O. Kim, D. H. Oh, D.-D.

Kim, J. S. Kim, B. K. Yoo and H.-G. Choi, Int. J. Pharm., 2009, 377, 1-8.

V. B. Junyaprasert, P. Singhsa, J. Suksiriworapong and D. Chantasart, Int. J. Pharm., 2012, 423, 303-311.

44 G. Cevc, A. Schätzlein and G. Blume, Journal of Controlled Release, 1995, 36, 3-16.

45 G. Cevc, D. Gebauer, J. Stieber, A. Schätzlein and G. Blume, Biochimica et Biophysica Acta (BBA)-Biomembranes, 1998, 1368, 201-215.

G. Cevc and G. Blume, Biochim. Biophys. Acta, 2004, 1663, 61-73.

G. Cevc, D. Gebauer, J. Stieber, A. Schätzlein and G. Blume, Biochim. Biophys. Acta, 1998, 1368, 201-215.

48 G. Cevc, A. Schätzlein and G. Blume, J. Control. Release, 1995, 36, 3-16.

G. Cevc, U. Vierl and S. Mazgareanu, Int. J. Pharm., 2008, 360, 18-28.

Y. Hiruta, Y. Hattori, K. Kawano, Y. Obata and Y. Maitani, J. Control. Release, 2006, 113, 146-154.

51 K. G. Lau, Y. Hattori, S. Chopra, E. A. O’Toole, A. Storey, T. T. Nagai and Y. Maitani, Int. J. Pharm., 2005, 300, 4-12.

52 A. Paul, G. Cevc and B. Bachhawat, Vaccine, 1998, 16, 188-195.

53 M. Trotta, E. Peira, M. E. Carlotti and M. Gallarate, Int. J. Pharm., 2004, 270, 119125.

54 G. Cevc and G. Blume Biochim. Biophys. Acta, 2001, 1514, 191-205.

P. Verma and K. Pathak, J. Adv. Pharm. Techno.l Res., 2010, 1, 274-282. 2007, 123, 148-154.

57 D. Ainbinder and E. Touitou, Drug Deliv., 2005, 12, 297-303.

58 N. Dayan and E. Touitou, Biomaterials, 2000, 21, 1879-1885.

59 C. Puglia, L. Rizza, M. Drechsler and F. Bonina, Drug Deliv., 2010, 17, 123-129.

60 S. Baboota, F. Shakeel, A. Ahuja and J. A. S. Shafiq, Acta Pharm., 2007, 57, 315-332.

61 S. Khandavilli and R. Panchagnula, J. Invest. Dermatol., 2007, 127, 154-162.

62 A. H. Elshafeey, A. O. Kamel and M. M. Fathallah, Pharm. Res., 26, 2446-2453.

63 D. Kumar, M. Aqil, M. Rizwan, Y. Sultana and M. Ali, Pharmazie, 2009, 64, 80-85.

64 S. Han, S. Kwon, Y. Jeong, E. Yu and S. Park, Int. J. Cosmetic Sci., 2014, 36, 588597.

65 L. B. Jensen, K. Petersson and H. M. Nielsen, Eur. J. Pharm. Biopharm., 2011, 79, $68-75$.

66 S. D. Mandawgade and V. B. Patravale, Int. J. Pharm., 363, 132-138.

67 K. A. Shah, A. A. Date, M. D. Joshi and V. B. Patravale, Int. J. Pharm., 2007, 345, 163-171.

68 R. Raj, P. Mongia, A. Ram and N. Jain, Artif. Cells Nanomed. Biotechnol., 2016, 44, 1434-1439.

69 Z. Yong-Tai, H. Meng-Qing, S. Li-Na, Z. Ji-Hui and F. Nian-Ping, J. Biomed. Nanotechnol., 2015, 11, 351-361.

70 J.-W. So, S. Kim, J.-S. Park, B.-H. Kim, S.-H. Jung, S.-C. Shin and C.-W. Cho, Pharm. Dev. Technol., 2010, 15, 415-420. 
71 A. Gulbake, A. Jain, P. Khare and S. K. Jain, J. Microencapsul., 2010, 27, 226-233.

72 D. Liu, Y. Ge, Y. Tang, Y. Yuan, Q. Zhang, R. Li and Q. Xu, J. Microencapsul., 2010, 27, 726-734.

73 Q. Lv, A. Yu, Y. Xi, H. Li, Z. Song, J. Cui, C. F. and G. Zhai, Int. J. Pharm., 2009, 372, 191-198.

74 S. T. Kim, D.-J. Jang, J. H. Kim, J. Y. Park, J. S. Lim, S. Y. Lee, K.-M. Lee, S.-J. Lim and C.-K. Kim, Pharmazie, 2009, 64, 510-514.

75 V. Sanna, A. Mariani, G. Caria and M. Sechi, Chem. Pharm. Bull., 2009, 57, 680-684.

76 N. Passerini, E. Gavini, B. Albertini, G. Rassu, M. Sabatino, V. Sanna, P. L. Giunchedi and Rodriguez, J. Pharm. Pharmacol., 2009, 61, 559-567.

77 M. R. Bhalekar, V. Pokharkar, A. Madgulkar, N. Patil and N. Patil, AAPS PharmSciTech, 2009, 10, 289-296.

78 G. A. Castro, A. L. L. Coelho, C. A. Oliveira, G. A. Mahecha, R. L. Oréfice and L. A. Ferreira, Int. J. Pharm. , 2009, 381, 77-83.

79 J. Liu and H. C. W. Hu, Q. Ni, H. Xu and X. Yang, , Int. J. Pharm., 2007, 328, 191195.

80 H. Chen, X. Chang, D. Du, W. Liu, J. Liu, T. Weng, Y. Yang, H. Xu and X. Yang, J. Control. Release, 2006, 110, 296-306.

81 P. V. Pople and K. K. Singh, AAPS PharmSciTech, 2006, 7, E63-E69.

82 V. Jenning, M. Schäfer-Korting and S. Gohla, J. Control. Release, 2000, 66, 115-126.

83 N. K. Garg, B. Singh, R. K. Tyagi, G. Sharma and O. P. Katare, Colloids Surf. B, 2016, 147, 17-24.

84 N. K. Garg, R. K. Tyagi, B. Singh, G. Sharma, P. Nirbhavane, V. Kushwah, S. Jain and O. P. Katare, Int. J. Pharm., 2016, 499, 301-320.

85 H. Chen, Y. Wang, Y. Zhai, G. Zhai, Z. Wang and J. Liu, Colloids Surf. A, 2015, 465, 130-136.

86 Y.-K. Lin, Z.-R. Huang, R.-Z. Zhuo and J.-Y. Fang, Int. J. Nanomed., 2010, 5, 117128.

87 M. J. Gomes, S. Martins, D. Ferreira, M. A. Segundo and S. Reis, Int. J. Nanomed., 2014, 9, 1231-1242.

88 M. Ricci, C. Puglia, F. Bonina, C. D. Giovanni, S. Giovagnoli and C. Rossi, J. Pharm. Sci., 2005, 94, 1149-1159.

89 C. Puglia, P. Blasi, L. Rizza, A. Schoubben, F. Bonina, C. Rossi and M. Ricci, Int. J. Pharm., 2008, 357, 295-304.

$90 \quad$ P. V. Pople and K. K. Singh, Int. J. Pharm., 2010, 398, 165-178.

91 K. Bhaskar, J. Anbu, V. Ravichandiran, V. Venkateswarlu and Y. M. Rao, Lipids Health Dis., 2009, 8, 6.

92 K. Bhaskar, C. K. Mohan, M. Lingam, S. J. Mohan, V. Venkateswarlu, Y. M. Rao, K. Bhaskar, J. Anbu and V. Ravichandran, Drug Dev. Ind. Pharm., 2009, 35, 98-113.

93 J.-Y. Fang, C.-L. Fang, C.-H. Liu and Y.-H. Su, Eur. J. Pharma. Biopharma., 2008, 70, 633-640.

94 E. Souto, S. Wissing, C. Barbosa and R. Müller, Int. J. Pharm., 2004, 278, 71-77.

95 P. Pathak and M. Nagarsenker, AAPS PharmSciTech, 2009, 10, 985-992.

96 Ü. Gönüllü, M. Üner, G. Yener, E. F. Karaman and Z. Aydoğmuş, Acta Pharm., 2015, 65, 1-13.

97 A. Manosroi, L. Kongkaneramit and J. Manosroi, Int. J. Pharm., 2004, 270, 279-286.

98 F. Maestrelli, M. L. González-Rodríguez, A. M. Rabasco and P. Mura, Int. J. Pharm., 2005, 298, 55-67.

99 B. McCormack and G. Gregoriadis, Int. J. Pharm., 1998, 162, 59-69.

100 Y. L. Loukas, V. Vraka and G. Gregoriadis, Int. J. Pharm., 1998, 162, 137-142. 
101 M. Foldvari, Pharm. Res., 1994, 11, 1593-1598.

102 N. Weiner, Int. J. Pharm., 1998, 162, 29-38.

103 K. Kriwet and C. C. Müller-Goymann, Int. J. Pharm., 1995, 125, 231-242.

104 H.-Y. Yu and P. Sun and W.-Y. Hou, Int. J. Pharm., 1998, 176, 133-136.

105 D. Yarosh, J. Klein, A. O'Connor, J. Hawk, E. Rafal, P. Wolf and X. P. S. Group, Lancet, 2001, 357, 926-929.

106 A. Saraswat, R. Agarwal, O. P. Katare, I. Kaur and B. Kumar, J. Dermatolog. Treat., 2007, 18, 40-45.

107 M. Manconi, C. Caddeo, C. Sinico, D. Valenti, M. C. Mostallino, G. Biggio and A. M. Fadda, Eur. J. Pharm. Biopharm., 2011, 78, 27-35.

108 G. M. E. Maghraby, A. C. Williams and B. W. Barry, J. Pham. Pharm. Sci., 1999, 51, 1123-1134.

109 G. M. E. Maghraby, A. C. Williams and B. W. Barry, Int. J. Pharm., 2000, 196, 6374.

110 S. Duangjit, P. Opanasopit, T. Rojanarata and T. Ngawhirunpat, AAPS PharmSciTech, 2013, 14, 133-140.

111 S. Jain, P. Jain, R. Umamaheshwari and N. Jain, Drug Dev. Ind. Pharm., 2003, 29, 1013-1026.

112 A. Gupta, G. Aggarwal, S. Singla and R. Arora, Sci. Pharm, 2012, 80, 1061-1080.

113 E. A. Essa, M. C. Bonner and B. W. Barry, J. Control. Release, 2004, 95, 535.

114 P. Verma and K. Pathak, Nanomedicine, 2012, 8, 489-496.

115 Y. Zhou, Y.-H. Wei, G.-Q. Zhang and X.-A. Wu, Arch. Pharm. Res., 2010, 33, 567574.

116 D. Paolino, G. Lucania, D. Mardente, F. Alhaique and M. Fresta, J. Control. Release, 2005, 106, 99.

117 M. M. Elsayed, O. Abdallah, V. Naggar and N. Khalafallah, Int. J. Pharm. Sci., 2007, 62, 133-137.

118 M. K. Chourasia, L. Kang and S. Y. Chan, Results Pharma. Sci., 2011, 1, 60-67.

119 Y.-P. Fang, Y.-B. Huang, P.-C. Wu and Y.-H. Tsai, Eur. J. Pharm. Biopharm., 2009, 73, 391-398.

120 A. S. Guinedi, N. D. Mortada, S. Mansour and R. M. Hathout, Int. J. Pharm., 2005, 306, 71-82.

121 A. Balasubramaniam, V. A. Kumar and K. S. Pillai, Drug Dev. Ind. Pharm., 28, 11811193.

122 A. Shahiwala and A. Misra, J. Pharm. Pharm. Sci., 2002, 5, 220-225.

123 D. A. van Hal, E. Jeremiasse, T. de Vringer, H. E. Junginger and J. A. Bouwstra, Eur. J. Pharm. Sci., 1996, 4, 147-157.

124 A. A. H. Sathali and G. Rajalakshmi, Int. J. Pharm. Tech. Res., 2, 2081-2089.

125 L. Tavano, P. Alfano, R. Muzzalupo and B. de Cindio, Colloids Surf. B, 97, 333-339.

126 S. Vyas and S. J. R. Singh, V. Mishra, S. Mahor, P. Singh, P. Gupta, A. Rawat and P. Dubey, Int. J. Pharm., 2005, 296, 80-86.

127 S. Jain, P. Singh, V. Mishra and S. Vyas, Immun. Lett., 2005, 101, 41-49.

128 J.-Y. Fang, C.-T. Hong, W.-T. Chiu and Y.-Y. Wang, Int. J. Pharm., 2001, 219, 6172.

129 B. Vora, A. J. Khopade and N. Jain, J. Control. Release, 1998, 54, 149-165.

130 J.-Y. Fang, S.-Y. Yu, P.-C. Wu, Y.-B. Huang and Y.-H. Tsai, Int. J. Pharm., 2001, 215, 91-99.

131 H. M. El-Laithy, O. Shoukry and L. G. Mahran, Eur. J. Pharm. Biopharm., 2011, 77, 43-55.

132 H. Ammar, M. Ghorab, S. El-Nahhas and I. Higaz, Int. J. Pharm., 2011, 405, 142-152. 
134 D. Verma and A. Fahr, J. Control. Release, 2004, 97, 55-66.

135 N. Dragicevic-Curic, D. Scheglmann, V. Albrecht and A. Fahr, J. Control. Release, 2008, 127, 59-69.

136 N. Dragicevic-Curic and V. A. a. A. F. D. Scheglmann, Colloids Surf. B, 2009, 70, 198-206.

137 M. Chen, X. Liu and A. Fahr, J. Biomed. Nanotechnol., 2010, 6, 577-585.

138 S. M. Shah and A. S. J. M. Ashtikar, D. T. Makhija, Y. Nikam, R. P. Gude, F. Steiniger, A. A. Jagtap, M. S. Nagarsenker and A. Fahr, Int. J. Pharm., 2015, 490, 391-403.

139 M. Kamran, A. Ahad, M. Aqil, S. S. Imam, Y. Sultana and A. Ali, Int. J. Pharm., 2016, 505, 147-158.

140 G. R. Qadri, A. Ahad, M. Aqil, S. S. Imam and A. Ali, Artif. Cells Nanomed. Biotechnol., 45, 139-145.

141 M. Liu and J. M. J. Fréchet, Pharm. Sci. Technol. Today, 1999, 2, 393-401.

142 V. V. K. Venuganti and O. P. Perumal, Int. J. Pharm., 2008, 361, 230-238.

143 V. V. K. Venuganti and O. P. Perumal, J. Pharm. Sci., 2009, 98, 2345-2356.

144 Z. Wang, Y. Itoh, Y. Hosaka, I. Kobayashi, Y. Nakano, I. Maeda, F. Umeda, J. Yamakawa, M. Kawase and K. Yag, J. Biosci. Bioeng., 2003, 95, 541-543.

145 A. R. Hegde, P. V. Rewatkar, J. Manikkath, K. Tupally, H. S. Parekh and S. Mutalik, Eur. J. Pharm. Sci., 2017, 102, 237-249.

146 S. Mutalik, U. Y. Nayak, R. Kalra, A. Kumar, R. V. Kulkarni and H. S. Parekh, Skin Res. Technol., 2012, 18, 101-107.

147 S. Mutalik, H. Parekh, Y. Anissimov, J. E. Grice and M. S. Roberts, Skin Pharmacol. Physiol., 2013, 26, 127-138.

148 C. Wright, US patent number 5,620.021., 1997.

149 R. Singhvi, J. Drug. Deliv. Sci. Technol. , 2006, 6, 72-75.

150 J. A. Simon, Menopause, 2006, 13, 22-231.

151 A. O. Abioye, S. Issah and A. T. Kola-Mustapha, Int. J. Pharm., 490, 490, 112--130.

152 T. A. Ahmed and M. Khalid, Life Sci., 2014, 110, 35-43.

153 T. Cerchiara, B. Luppi, F. Bigucci, I. Oreinti and V. Zecchi, J. Pharm. Pharmacol., 2002, 54, 1453-1459.

154 S. Jana, S. Manna, A. K. Nayak, K. K. Sen and S. K. Basu, Colloids Surf. B, 2014, 114, 36-44.

155 S. K. H. Khalil, G. S. El-Feky, S. T. El-Banna and W. A. Khalil, Carbohydr. Polym., 2012, 90, 1244-1253.

156 T. Şenyiğit, F. Sonvico, S. Barbieri, ., O. Ozer, P. Santi and P. Colombo, J. Control. Release, 2010, 142, 368-373.

157 Y. Wang, W. Su, Q. Li, C. Li, H. Wang, Y. Li, Y. Cao, J. Chang and L. Zhang, Int. J. Pharm., 2013, 441, 748.

158 P.-W. Lee, S.-F. Peng, C.-J. Su, F.-L. Mi, H.-L. Chen, M.-C. Wei, H.-J. Lin and H.-W. Sung, Biomaterials, 2008, 29, 742-751.

159 J. Shim, H. Seok Kang, W. S. Park, S. H. Han, J. Kim and I. S. Chang, J. Control. Release, 2004, 97, 477-748.

160 P. Shah, P. Desai, A. Patel and M. Singh, Biomaterials, 2012, 33, 1607-1617.

161 X. Wu, G. J. Price and R. H. Guy, Mol. Pharm., 2009, 6, 1441-1448.

162 M. Guyot and F. Fawaz, Int. J. Pharm., 2000, 204, 171.

163 M. V. Bentley, J. M. Marchetti, N. Ricardo, Z. Ali-abi and J. H. Collett, Int. J. Pharm., 1999, 193, 49-55. 
164 O. Pillai and R. Panchagnula, J. Control. Release, 2003, 89, 127.

165 A. S. Chauhan, S. Sridevi, K. B. Chalasani, A. K. Jain, S. K. Jain, J. N. K. and P. V. Diwan, J. Control. Release, 2003, 90, 335-343.

166 C. Yiyun, M. Na, X. Tongwen, F. Rongqiang, W. Xueyuan, W. Xiaomin and W. Longping, J. Pham. Sci., 2007, 96, 595-602.

167 K. Borowska, S. Wołowiec, A. Rubaj, K. Głowniak, E. Sieniawska and S. Radej, Int. J. Pharm., 2012, 426, 280-283.

168 Y. Huang, F. Yu, Y.-S. Park, J. Wang, M.-C. Shin, H. S. Chung and V. C. Yang, Biomaterials, 2010, 31, 9086-9091.

169 G. Sonavane, K. Tomoda, A. Sano, H. Ohshima, H. Terada and K. Makino, Colloids Surf. B, 2008, 65, 1-10.

170 F. F. Larese, F. D’Agostin, Crosera M. , G. Adami, N. Renzi, M. Bovenzi and G. Maina, Toxicol., 2009, 255, 33-37.

171 F. L. Filon, F. D’Agostin, M. Crosera, G. Adami, M. Bovenzi and G. Maina, Toxicol. In Vitro, 2009, 23, 574-579.

172 F. L. Filon, G. Maina, G. Adami, M. Venier, N. Coceani, R. Bussani, M. Massiccio, P. Barbieri and P. Spinelli, Int. Arch. Occup. Envi., 2004, 77, 85-89.

173 H. I. Labouta, L. K. El-Khordagui, T. Kraus and M. Schneider, Nanoscale,, 2011, 3, 4989-4999.

174 R. Fernandes and O. L. M. N. R. Smyth, S. Nitti, A. Heuer-Jungemann, M. R. Ardern-Jones and A. G. Kanaras, Small, 2015, 11, 713-721.

175 P. F. Hsiao, S. Peng, T.-C. Tang, S.-Y. Lin and H.-C. Tsai, Int. J. Nanomed., 2016, 11, 1867.

176 Y.-J. Kim, B. Kim, J. W. Kim, G. Nam, H.-S. Jang, K. S.-W. and U. Jeong, Colloids Surf. B, 2015, 135, 324-331.

177 B. Mandal, A. P. Rameshbabu, S. Dhara and S. Pal, Polymer, 2017, 120, 9-19.

178 S. Moritake, S. Taira, Y. Ichiyanagi, N. Morone, S.-Y. Song, T. Hatanaka, S. Yuasa and M. Setou, J. Nanosci. Nanotechnol., 2007, 7, 937-944.

179 Y.-F. Rao, W. Che, X.-G. Liang, Y.-Z. Huang, J. Miao, L. Liu, Y. Lou, X.-G. Zhang, B. Wang, R.-K. Tang, Z. Chen and X.-Y. Lu, Small, 2014, 11, 239-247.

180 S. Ramadan, L. Guo, Y. Li, B. Yan and W. Lu, Small, 2012, 8, 3143-3150.

181 S. Mutalik, P. K. Shetty, A. Kumar, R. Kalra and H. S. Parekh, Drug Deliv., 2014, 21, 44-54.

182 A. Hasanovic, M. Zehl, G. Reznicek and C. Valenta, J. Pharm. Pharmacol., 2009, 61, 1609-1616.

183 J. Vandervoort, Eur. J. Pharm. Biopharm., 2004, 57, 251-261.

184 D.-G. Kim, Y.-I. Jeong, C. Chai, S.-H. Roh, S.-K. Kang, M.-K. Jang and J.-W. Nah, Int. J. Pharm. , 2006, 319, 130-138.

185 S. Ozbas-Turan and A. Julide, Drug. Deliv. , 2011, 18, 215-222.

186 S. Özbaş-Turan, J. Akbuğa and A. D. Sezer, Oligonucleotides, 2010, 20, 147-153.

187 Q. Tan, W. Liu, C. Guo and G. Zhai, Int. J. Nanomedince, 2011, 6, 1621-1630.

188 H. Tsujimoto, K. Hara, Y. Tsukada, C. C. Huang, Y. Kasashima, M. Arakaki, H. Okayasu, H. Mimura and N. Miwa, Bioorg. Med. Chem. Lett. , 2007, 17, 4771-4777.

189 K. Tomoda, H. Terashima, K. Siuzuki, T. Inagi, H. Terada and K. Makino, Colloids Surf. B, 2011, 88, 706-710.

190 R. Alvarez-Roman, Eur. J. Pharm. Biopharm., 2001, 52, 191.

191 A. Garg, G. Rai, S. Lodhi, A. P. Jain and A. K. Yadav, Drug Deliv., 2016, 23, 1525 1535 . 
192 Y.-C. Kim, M. J. Ludovice and M. R. Prausnitz, J. Biomed. Nanotechnol., 2010, 6, 612.

193 M. B. Dohnert, M. Venâncio, J. C. Possato, R. C. Zeferino, L. H. Dohnert, A. I. Zugno, C. T. De Souza, M. M. Paula and T. F. Luciano, Int. J. Nanomed., 2012, 7, 1651.

194 L. A. Jackson, G. Austin, R. T. Chen, R. Stout, F. DeStefano, G. J. Gorse, F. K. Newman, O. Yu and B. G. Weninger, Vaccine, 2001, 19, 4703-4709.

195 S. E. Cross and M. S. Roberts, Current Drug Delivery, 2004, 1, 81-92

196 I. Som, K. Bhatia and M. Yasir, J Pharm Bioallied Sci., 2010, 4, 2-9.

197 J. Ghel, Methods Mol. Biol., 2008, 423, 351.

198 J. W. Lee, P. Gadiraju, J.-H. Park, M. G. Allen and M. R. Prausnitz, J. Control. Release, 2011, 154, 58-68.

199 G. Levin, A. Gershonowitz, H. Sacks, M. Stern, A. Sherman, S. Rudaev, I. Zivin and M. Phillip, Pharm. Res., 2005, 22, 550.

200 J. Y. Fan, W. R. Lee, S. C. Shen, H. Y. Wang, C. L. Fang and C. H. Hu, J. Control. Release, 2004, 100, 75.

201 W. R. Lee, S. C. Shen, H.-H. Lai, C. H. Hu and J. Y. Fang, J. Control. Release, 2001, 75, 155-166.

202 W. R. Lee, S. C. Shen, C. L. Fang, R. Z. Zhou and J. Y. Fang, Lasers Surg. Med,, 2008, 40, 468-476.

203 Y. G. Bachhav, S. Summer, A. Heinrich, T. Bragagan, C. Bohler and Y. N. Kalia, J. Control. Release, 2010, 146, 31-36.

204 Y. N. Kalia, Y. G. Bachhav, T. Bragagan and C. Bohler, J. Drug. Deliv. Technol., 8, 26-31.

205 Y. G. Bachhav, A. Heinrich and Y. N. Kalia, Eur. J. Pharm. Biopharm., 78, 404-414.

206 C. Gomez, A. Costela, I. Garcia-Moreno, F. Llanes, J. M. Teijon and D. Blanco, Lasers Surg. Med., 2008, 40, 6-12.

207 W. R. Lee, S. C. Shen, K. H. Wang, C. H. Hu and J. Y. Fan, J. Pharm. Sci., 2002, 91, 1613.

208 E. Larraneta, R. E. M. Lutton, A. D. Woolfson and R. F. Donnelly, Mater. Sci. Eng. R, 2016, 104, 1-32.

209 M. S. Gerstel and V. A. Place, US Patent 3.964.482, 1976.

210 S. Henry, D. V. McAllister, M. G. Allen and M. R. Prausnitz, J. Pharm. Sci., 1998, 87, 922.

211 S. Liu, M.-N. Jin, Y.-S. Quan, F. Kamiyama, H. Katsumi, T. Sakane and A. Yamamoto, J. Control. Release, 2012, 161, 933-941.

212 M. M. Chen, M.-H. Liang, K.-Y. Lai and E. Pramudityo, Biomacromolecules, 2012, 13, 4022-4031.

213 M. C. Chen, M. H. Ling, K. W. Wang, Z. W. Lun, B. H. Lai and D. H. Chen, Biomacromolecules, 2015, 16, 1598-1607.

214 R. F. Donnelly, T. R. Sing, M. J. Garland, K. Migalska, Majithiya R, C. McCrudden, P. Kole, T. Mahmood, H. McCarthy and A. Woolfson, Adv. Funct. Mater., 2012, 22, 4879-4890.

215 M. J. Garland, E. Caffarel-Salvador, K. Migalska, A. D. Woolfson and R. F. Donnelly, J. Control. Release, 2012, 159, 52-59.

216 R. F. Donnelly, C. McCrudden, Ahlam Zaid Alkilani, Eneko Larrañeta, Emma McAlister, Aaron J. Courtenay, Mary-Carmel Kearney, Thakur Raghu Raj Singh, Helen O. McCarthy, Victoria L. Kett, Ester Caffarel-Salvador, Sharifa Al-Zahrani and A. D. Woolfson, Plos One, 2014, 9, e111547. 
217 E. Larraneta, R. E. M. Lutton, A. J. Brady, E. M. Vicente-Perez, A. D. Woolfson, R. S. Thakur and R. F. Donnelly, Macromol. Mater. Eng., 2015, 300, 586-595.

218 J. G. Hardy, Eneko Larrañeta, R. F. Donnelly, N. McGoldrick, K. Migalska, M. T. C. McCrudden, Nicola J. Irwin, L. Donnelly and C. P. McCoy, Mol. Pharm., 2016, 13, 907-914.

219 H. Kim, H. Lee, K.-Y. Seong, E. Lee, S. Y. Yang and J. Yoon, Adv. Healthcare Mater., 2015, 4, 2071-2077.

220 F. Teodorescu, G. Guéniat, C. Foulon, M. Lecoeur, A. Barras, S. Boulahneche, M. S. Medjram, T. Hubert, A. Abderrahmani, R. Boukherroub and S. Szunerits, J. Control. Release, 2017, 245, 137-146.

221 F. Teodurescu, Y. Oz, G. Quéniat, A. Abderrahmani, C. Foulon, M. Lecoeur, R. Sanyal, A. Sanyal, R. Boukherroub and S. Szunerits, J. Control. Release, 2017, 246, 164-173.

222 A. C. Watkinson, in Topical and tansdermal drug delivery-Principles and Practice, ed. H. A. W. E. C. Benson, John Wiley \& Sons Inc:, Hoboken, NJ, 2012, pp. 357-366. 